\title{
Development of an Optimized Drying Process for the Recovery of Bioactive Compounds from the Autumn Fruits of Berberis vulgaris L. and Crataegus monogyna Jacq.
}

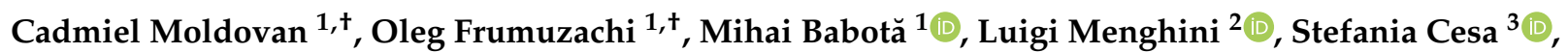 \\ Alexandru Gavan ${ }^{1}{ }^{1}$, Cristian R. Sisea ${ }^{4,5}$, Corneliu Tanase ${ }^{6}{ }^{(0)}$, Maria Inês Dias ${ }^{7}$, Carla Pereira ${ }^{7}$, \\ Isabel C.F.R. Ferreira ${ }^{7} \mathbb{D}$, Gianina Crișan ${ }^{1}$, Andrei Mocan ${ }^{1,4, * \mathbb{C}}$ and Lillian Barros ${ }^{7} \mathbb{C}$
}

Citation: Moldovan, C.; Frumuzachi, O.; Babotă, M.; Menghini, L.; Cesa, S.; Gavan, A.; Sisea, C.R.; Tanase, C.;

Dias, M.I.; Pereira, C.; et al.

Development of an Optimized

Drying Process for the Recovery of

Bioactive Compounds from the Autumn Fruits of Berberis vulgaris L. and Crataegus monogyna Jacq. Antioxidants 2021, 10, 1579. https:// doi.org/10.3390/antiox10101579

Academic Editor: Evangelos Zoidis

Received: 1 September 2021

Accepted: 27 September 2021

Published: 7 October 2021

Publisher's Note: MDPI stays neutral with regard to jurisdictional claims in published maps and institutional affiliations.

Copyright: (C) 2021 by the authors. Licensee MDPI, Basel, Switzerland. This article is an open access article distributed under the terms and conditions of the Creative Commons Attribution (CC BY) license (https:/ / creativecommons.org/licenses/by/ $4.0 /)$.
1 Faculty of Pharmacy, "Iuliu Hațieganu" University of Medicine and Pharmacy, 8 Victor Babeș Street, 400012 Cluj-Napoca, Romania; cadmiel.moldovan@umfcluj.ro (C.M.); oleg.frumuzachi@elearn.umfcluj.ro (O.F.); mihai.babota@umfcluj.ro (M.B.); gavan.alexandru@umfcluj.ro (A.G.); gcrisan@umfcluj.ro (G.C.)

2 Department of Pharmacy, Botanic Garden "Giardino dei Semplici", Università Degli Studi "Gabriele d'Annunzio", Via dei Vestini 31, 66100 Chieti, Italy; lmenghini@unich.it

3 Department of Drug Chemistry and Technologies, University "Sapienza" of Rome, P.le Aldo Moro 5, 00185 Rome, Italy; stefania.cesa@uniroma1.it

4 Laboratory of Chromatography, Institute of Advanced Horticulture Research of Transylvania, University of Agricultural Sciences and Veterinary Medicine, 400372 Cluj-Napoca, Romania; cristian.sisea@usamvcluj.ro

5 Faculty of Horticulture, University of Agricultural Sciences and Veterinary Medicine Cluj-Napoca, 400372 Cluj-Napoca, Romania

6 Faculty of Pharmacy, "George Emil Palade" University of Medicine, Pharmacy, Science and Technology, 38 Gheorghe Marinescu Street, 540142 Târgu-Mureș, Romania; corneliu.tanase@umfst.ro

7 Centro de Investigação de Montanha (CIMO), Instituto Politécnico de Bragança, Campus de Santa Apolónia, 5300-253 Bragança, Portugal; maria.ines@ipb.pt (M.I.D.); carlap@ipb.pt (C.P.); iferreira@ipb.pt (I.C.F.R.F.); lillian@ipb.pt (L.B.)

* Correspondence: andrei.mocan@usamvcluj.ro

+ These authors contributed equally to this work.

Abstract: Hot air drying has proven to be an efficient method to preserve specific edible plant materials with medicinal properties. This is a process involving chemical, physical, and biological changes in plant matrices. Understanding these processes will lead to an improvement in the yields of bioactive compounds. This study aims to optimize the drying process of two species' fruits used in folk medicine, Berberis vulgaris and Crataegus monogyna. The optimized extracts' antioxidant capacity was assessed using various assays, with the barberry extract showing very good activity $(50.85,30.98$, and $302.45 \mathrm{mg} \mathrm{TE} / \mathrm{g} \mathrm{dw}$ for DPPH, TEAC, and FRAP assays, respectively). Both species exerted good fungal $\alpha$-glucosidase inhibitory activity ( $\mathrm{IC}_{50}=0.34$ and $0.56 \mathrm{mg} / \mathrm{mL}$, respectively) but no activity on mammalian $\alpha$-glucosidase. Additionally, this study identified and quantified the main bioactive compounds. The results presented herein are a breakthrough in industrializing this drying process. Additional studies are necessary to mechanistically understand the drying process involved in these plant materials.

Keywords: drying process optimization; barberry; hawthorn; antioxidant activity; autumn fruits

\section{Introduction}

Medicinal plants have traditionally been used since the earliest times for the treatment of a wide range of ailments. Many of them are appreciated not only for their nutritional value but also for their organoleptic characteristics, for which they are used in dishes [1]. One of the most used methods for plant conservation, whether for medicinal or culinary purposes, is the drying process. Although drying is at first glance a process that involves the removal of water from the plant material, there are many physical, chemical, and biological 
transformations that occur during this process. Moreover, through drying, the water activity and moisture content of the foods are reduced, so the growth of microorganisms in the foods is largely prevented/postponed [2].

Numerous drying techniques have been developed and used for the dehydration of vegetal products over the years. The most relevant techniques involved in vegetal product drying are hot air drying, spray drying, freeze-drying, and osmotic dehydration [3]. Hot air drying is a traditional drying method in fruit dehydration. Through the hot air drying process, the vegetables are dried to enhance storage stability, minimize packaging requirements, and reduce transport cost. Currently, the hot air drying process is the main drying method used in vegetable dehydration. In this process, the pretreated fruits are subjected to hot airflow of $50-90^{\circ} \mathrm{C}$. Heat can be transferred from hot air to the vegetables, and when the heat is absorbed by the materials, two types of moisture diffusion occur. One process is external diffusion, in which moisture moves from the material surface to the dry medium. The other process is internal diffusion, in which the internal moisture moves to the material surface. These two diffusion processes develop at the same time until the moisture content decreases to the level at which the materials can be stored safely [4]. In this study, the main process in vegetable dehydration, the air drying technique, was chosen, which is a well-established technology owing to the availability of the necessary equipment and facilities.

Significant evidence has been gathered that indicates the key role of reactive oxygen species (ROS) and other oxidants in causing numerous ailments and diseases [5]. This proof has brought the attention of scientists to an appreciation of antioxidants for the prevention and treatment of diseases and maintenance of human health. The human body has an inherent antioxidative mechanism and many of the biological functions such as the anti-carcinogenic, anti-mutagenic, and anti-aging responses originate from this property. Antioxidants stabilize or deactivate free radicals, often before they attack targets within biological cells. Recently, interest in naturally occurring antioxidants has considerably increased for use in food, cosmetics, and pharmaceutical products because they possess activities that provide enormous potential to correct imbalances [6].

The genus Berberis consists of around 500 species of widely distributed 1-5 m tall evergreen shrubs [7]. The different plants of the genus Berberis can be found in many regions of the world, although their main distribution is in the Northern Hemisphere, more exactly, in the Himalayan region. The first mention of these plants was made in medieval writings. In the first century A.C. the Greeks were familiar with a Berberis extract, which they named "Indian Lyceum", while the Arabs termed it "Honduras" [8]. Some Berberis sp. are commonly used in folk medicine for the treatment of gastric and duodenal ulcers, chronic diarrhea, and rheumatic conditions of the joints. Notably, despite the fact that the Berberis genus is known for its specific, well-documented alkaloids, berberine and berbamine, these compounds are found only in the stems and roots [9].

Among the many species of this genus, Berberis vulgaris L. is a well-known shrub native to central and southern Europe, western Asia, and northwest Africa. It is known under the names of "common barberry", "European barberry", "jaundice berry", and "ambarbaris". The biggest producer of B. vulgaris in the world is Iran, with 11,000 hectares of land under cultivation. Moreover, $\sim 10,000$ tons of dried B. vulgaris fruits are produced per year in Iran [10]. The fruit, known as barberry, is an oblong red berry 7-10 $\mathrm{mm}$ in length and 3-5 $\mathrm{mm}$ in width, which ripens usually at the end of summer/beginning of autumn. Historical testimonies revealed that drinking barberry juice can ameliorate fever, thirst, and even inflammation [8]. Additionally, the derivatives of barberry are used to produce traditional products such as marmalade, jam, carbonated drinks, and sauces. The anthocyanins extracted from the fruits are industrially used as coloring agents for the preparation of food products, such as juices [10].

The medicinal use of the fruits of $B$. vulgaris in the literature is lacking, but there are many other traditional uses cited for the other parts of the plant (e.g., roots and bark), but they are not the object of this study. 
Regarding the chemical composition of barberry fruits, the scientific data shows that they contain little or no alkaloids. However, they contain a great amount of phenolics, gum, pectin, oleoresins, and organic acids [11].

Several pharmacological effects have been demonstrated for the barberry fruit extract. Among these are cytoprotective and antioxidant actions [12] and anticholinergic and antihistaminergic effects [11].

Hawthorn is a common name of all species in the genus Crataegus. The generic name, Crataegus, comes from the Greek $k \rho \alpha$ á $\varsigma_{\zeta}$, meaning hard or strong, referring to the plant's wood. Nowadays, it is known that almost 20 species of hawthorn are used as drug materials or herbal medicines worldwide. Some of them are listed in the pharmacopoeias of various countries. Their use for the treatment of cardiovascular disease began in the late 1800s. In traditional Chinese medicine (TCM), hawthorn fruits are used to stimulate digestion and to improve blood circulation. Additionally, in European folk medicine, hawthorn is used as a cardiotonic, astringent, anti-spasmodic, and diuretic agent [13,14].

The red fruit (frequently called "haw") of Crataegus monogyna Jacq. (common hawthorn), which ripens generally in the middle of autumn, is traditionally used for different culinary purposes, such as the preparation of jellies, jams, and syrups [14,15].

Moreover, the fruits from C. monogyna are mentioned in different pharmacopeias worldwide such as the European Pharmacopeia or British Pharmacopeia [16]. In Romania, the name of the species is "Păducel" or "Mărăcine". The pharmacological proprieties of hawthorn fruit extracts are usually attributed to proanthocyanidins and other glycosylated derivatives of flavonoids [17]. Various studies have aimed to assess the in vivo or in vitro activities of these compounds towards cardiovascular, digestive, or reproductive ailments. Furthermore, it was demonstrated that extracts from C. monogyna fruits can ameliorate inflammation, exert antimicrobial activity, and can be used as an adjuvant in cancer radiotherapy.

Given these important characteristics, the aims of this study were to assess the effects of drying conditions on two traditionally used fruits in Romania (barberry (B. vulgaris) and hawthorn (C. monogyna)) and to select the proper conditions with respect to time of drying and air temperature.

\section{Materials and Methods}

\subsection{Chemicals}

Acetone, Hydrochloric acid (37\%), Folin-Ciocâlteu reagent, methanol and ethanol were purchased from Merck (Darmstadt, Germany). 2,2-diphenyl-1-(2,4,6-trinitro-phenyl) hydrazine (DPPH), 2,5,7,8-tetramethylchromane-2-carboxylic acid (Trolox) (97\%), ferric chloride, sodium carbonate, 2,4,6-Tris(2-pyridyl)-S-triazine (TPTZ) ( $\geq 99 \%)$, dimethyl sulfoxide (DMSO) ( $\geq 99 \%$ ), 3,4-Dihydroxy-L-phenylalanine (L-DOPA) ( $\geq 98 \%$ ), 6-hydroxydiammonium 2,2'-azinobis(3-ethylbenzothiazoline-6-sulfonate) (ABTS) (>98\%), mushroom tyrosinase, phosphate buffer, and kojic acid were purchased from Sigma (Sigma Aldrich Chemie $\mathrm{GmbH}$, Schnelldorf, Germany). Aluminum chloride ( $\geq 98 \%$ ) was acquired from Carl Roth (Karlsruhe, Germany). Water was of Milli-Q-quality. All solvents were of LC grade and all reagents were of analytical grade.

\subsection{Sample Preparation}

The plant materials obtained from different locations in Abruzzo Region, Italy and Cluj County, Romania were refrigerated at $5{ }^{\circ} \mathrm{C}$ to prevent additional damage of samples. Fruits with undesirable aspects (unripe and burst characteristics) were removed. After identification, fruit samples were stored in the Botany Department's Herbarium, Faculty of Pharmacy, Cluj-Napoca.

\subsection{Drying Procedure}

The first step of the procedure was represented by some preliminary experiments that generated data (not shown) on the critical process parameters and quality attributes of the 
plant-derived products (e.g., drying time, air flow, air temperature, distance between fruits samples). Subsequently, the drying strategy was developed. The software MODDE Pro 11.0 (Sartorius, Sweden) was used to develop and analyze the design of the experiments and to define the processes and the optimal drying parameters.

For the drying procedure, an oven dryer (Excalibur Food Dehydrator, Sacramento, CA, USA) was used at three different temperature levels $\left(50,60\right.$, and $\left.70{ }^{\circ} \mathrm{C}\right)$. The relative air humidity and the ambient air temperature of the environment where the dryer was operating were $40-50 \%$ and $16-22{ }^{\circ} \mathrm{C}$, respectively. The air flow temperature was accurately monitored over time. To record weight changes in the samples during drying, a balance (Adam PW254, Adam Equipment Co. Ltd., Milton Keynes, UK) with a sensitivity of $1 \mathrm{mg}$ was used. Samples' weight was checked at 4, 8, 12, 18, 24, 36, and $48 \mathrm{~h}$. A steady state condition was achieved in the dryer system at the beginning of the experiments. The fruits ( $5 \mathrm{~g} /$ sample) were spread uniformly on a perforated tray and subsequently inserted into a preheated oven.

\subsection{The Procedure for Extraction}

The following method was employed for the extraction: dried fruits' samples were ground and homogenised using a mill, namely Retsch Grindomix GM200 (Haan, Germany). Fifty $\mathrm{mL}$ of $70 \%(v / v)$ ethanol were added to the previously obtained powder and for homogenization, a vortex apparatus (Velp Scientifica Classic, Bohemia, NY, USA) was used. The mixture was ultrasonicated for $30 \mathrm{~min}$ at $50{ }^{\circ} \mathrm{C}$ and filtered using a water vacuum filter. The solution was made up with EtOH $70 \%$ to a final volume of $50 \mathrm{~mL}$.

The reconstitution of extracts was done as follows: for total bioactive compound quantification and for antioxidant activity, the dry weight extract was redissolved in $\mathrm{EtOH}$ $70 \%$ and for the enzymatic assays the dry weight extract was redissolved in water with $5 \%$ DMSO.

\subsection{Analysis of Phenolic Compounds}

The polyphenolic profile was determined by means of an LC-DAD-ESI/MSn (Dionex Ultimate 3000 UPLC, Thermo Scientific, San Jose, CA, USA) using the previously described method by Bessada et al. (2016) [18]. The extracts were redissolved with ethanol:water $(80: 20, v / v)$ at a concentration of $50 \mathrm{mg} / \mathrm{mL}$. Online detection was carried out by DAD (preferred wavelengths of 280, 330, and $370 \mathrm{~nm}$ ) coupled with a mass spectrometer (MS). MS detection was carried out using a Linear Ion Trap LTQ XL MS acquired from Thermo Finnigan (San Jose, CA, USA) in negative mode with an ESI source.

Based on polyphenol's chromatographic behavior and UV-vis and mass spectra, it was possible to identify the compounds comparing the data obtained with standard compounds, when available. The acquisition of data was performed with an Xcalibur ${ }^{\circledR}$ data system (Thermo Finnigan, San Jose, CA, USA). Based on the UV-vis signal, a 7-level calibration curve for each available phenolic compound was depicted in order to perform quantitative analysis. If a commercial standard compound was not available, the quantification was carried out using the calibration curve of the most similar available standard. Finally, the results were expressed as $\mathrm{mg} / \mathrm{g}$ of extract.

\subsection{Quantitative Determination Total Flavonoid Content (TFC) and Total Phenolic Content (TPC)}

The total phenolic content (TPC) of the extracts was determined using Folin-Ciocâlteu method, previously described by Mocan et al. (2016) [19]. Briefly, $100 \mu \mathrm{L}$ of Folin-Ciocâlteu reagent (diluted 1:10 with distilled water) were mixed with $20 \mu \mathrm{L}$ of each sample in a 96 well plate and incubated at room temperature. A solution of sodium carbonate $(7.5 \%$ $w / v, 80 \mu \mathrm{L}$ ) was added after $3 \mathrm{~min}$ to the wells and the mixture was incubated once again. After $30 \mathrm{~min}$, the absorbance of the mixture was measured at $760 \mathrm{~nm}$, using a SPECTROstar Nano microplate reader (BMG Labtech, Offenburg, Germany). Gallic acid was used as a reference standard and the TPC results of the extracts were expressed as milligrams of 
gallic acid equivalents (GAE)/gram of dry weight (dw) of raw fruits (mg GAE/g dw) or/gram of dry weight of optimized lyophilized extract (mg GAE/g dw).

The crude extracts' total flavonoid content (TFC) was assessed using a method previously reported by Mocan et al. (2017) [20]. Briefly, to $100 \mu \mathrm{L}$ of sample were added $100 \mu \mathrm{L}$ of $2 \% \mathrm{AlCl}_{3}$ aqueous solution in a 96 well plate. After $15 \mathrm{~min}$ of incubation in a dark place and at room temperature, the absorbance was read at $420 \mathrm{~nm}$ using a microplate reader, namely SPECTROstar Nano (BMG Labtech, Offenburg, Germany). Quercetin was used as a reference standard and the TFC results of the extracts were expressed as milligrams of quercetin equivalents $(\mathrm{QE})$ /gram of dry weight $(\mathrm{dw})$.

\subsection{Antioxidant Capacity Assays}

ABTS radical cation scavenging activity (TEAC), DPPH radical scavenging activity (DPPH) and ferric-reduction antioxidant power (FRAP) were used to assess the antiradical activity of the samples. A thiobarbituric acid reactive substances (TBARS) assay was used to analyze the inhibition of the lipid peroxidation process. Furthermore, the oxidative hemolysis inhibition assay (OxHLIA) was applied in order to determine the relevance of the in vivo inhibition of the free radicals.

\subsubsection{DPPH Radical Scavenging Activity Assay (DPPH)}

DPPH radical scavenging activity assay was assessed by a method described earlier by Moldovan et al. (2021) [21] with some modifications. Briefly, $30 \mu \mathrm{L}$ of sample solution and $0.004 \%$ DPPH radical solution (5 mg of DPPH diluted in $5 \mathrm{~mL}$ of absolute $\mathrm{MeOH}$, followed by a 25 -fold dilution of $1 \mathrm{~mL}$ DPPH solution) was incubated in a dark place at around $20-22{ }^{\circ} \mathrm{C}$. After $30 \mathrm{~min}$, the absorbance of the samples was measured at $515 \mathrm{~nm}$. DPPH radical scavenging activity was expressed in milligrams of trolox equivalents (TE)/gram of dry weight $\mathrm{mg} \mathrm{TE} / \mathrm{g} \mathrm{dw}$ ).

\subsubsection{Trolox Equivalent Antioxidant Capacity (TEAC) Assay}

A TEAC assay was assessed by a method previously described by Mocan et al. (2014) [22]. In brief, $20 \mu \mathrm{L}$ of sample and $200 \mu \mathrm{L}$ of radical solution, consisting of ABTS stock solution: $\mathrm{K}_{2} \mathrm{~S}_{2} \mathrm{O}_{8}$ stock solution (1:1) diluted 1:5 with water, were incubated for 6 min. The scavenge activity of antioxidants against $\mathrm{ABTS}^{+}$radical was measured at $760 \mathrm{~nm}$. The antioxidant activity according to TEAC assay was expressed as milligrams of trolox equivalents (TE) per gram of dry weight $(\mathrm{dw})$.

\subsubsection{Ferric Reducing Antioxidant Power Assay (FRAP)}

A FRAP assay was conducted as previously reported by Mocan et al. (2018) [23] with some modifications. In brief, a FRAP reagent was made by mixing $300 \mathrm{mM}$ acetate buffer ( $\mathrm{pH}$ 3.6), $10 \mathrm{mM}$ TPTZ reagent (31.23 $\mathrm{mg}$ TPTZ diluted in $10 \mathrm{~mL}$ of $40 \mathrm{mM} \mathrm{HCl}$ ), and $20 \mathrm{mM} \mathrm{FeCl}_{3}$ solution at a ratio of 10:1:1 (v:v:v). A sample solution amounting to $25 \mu \mathrm{L}$ and $175 \mu \mathrm{L}$ of FRAP reagent were mixed in a 96 well plate and incubated in a dark place at $20-22{ }^{\circ} \mathrm{C}$. After $30 \mathrm{~min}$, the absorbance of the samples was measured at $593 \mathrm{~nm}$. FRAP antioxidant activity was expressed as milligrams of trolox equivalents (TE)/gram of dry weight (mg TE/g dw).

\subsubsection{Thiobarbituric Acid Reactive Substances Assay (TBARS)}

TBARS assay was conducted as previously described by Souilem et al. (2017) [24] using porcine brain homogenates. Following this method, the absorbance of malondialdehyde-2thiobarbituric acid [MDA-TBA] complex found in the supernatant at the end of the assay was measured at $532 \mathrm{~nm}$. The concentration of the sample that inhibited lipid peroxidation in proportion of $50 \%$ was taken as the $\mathrm{EC}_{50}$ value, expressed in $\mu \mathrm{g} / \mathrm{mL}$. Trolox was used as a positive control. 


\subsubsection{Oxidative Hemolysis Inhibition Assay (OxHLIA)}

In order to obtain solutions with a final concentration ranging from 12.5 to $125 \mu \mathrm{g} / \mathrm{mL}$, $100 \mathrm{mg}$ of each extract were dissolved in phosphate-buffered saline (PBS). Oxidative hemolysis was measured by a method described by Takebayashi et al. (2012), using ovine erythrocyte solution [25]. Different extract concentrations and their afferent $\mathrm{Ht}_{50}$ values were used to infer the concentration of the extract capable of $60 \mathrm{~min} \Delta \mathrm{t}$ hemolysis retardation [26]. Thus, the extract concentrations required to keep $50 \%$ of the erythrocyte population intact for 60 min were expressed as $E_{50}$ values $(\mu \mathrm{g} / \mathrm{mL})$, with Trolox being used as a positive control.

\subsection{Cytotoxic Activity}

In order to asses cytotoxic activity, concentrations ranging from 6.25 to $400 \mu \mathrm{g} / \mathrm{mL}$ were obtained from re-dissolving the extracts in distilled water and further dilution. Evaluation of the cytotoxic properties of the extracts was done on human tumor cell lines (breast adenocarcinoma-MCF-7, non-small cell lung cancer-NCI-H460, cervical carcinomaHeLa, and hepatocellular carcinoma-HepG2) and a non-tumour cell line-PLP2-using a method described by Abreu et al. (2011) [27].

Sulforhodamine B assay was performed using a method described by Barros et al. (2013) [28] using Ellipticine as positive control, and a negative control provided by each suspension of cells. The results were expressed as $\mathrm{GI}_{50}$ values, which represent the concentrations at which $50 \%$ of cell proliferation was inhibited.

\subsection{Anti-Inflammatory Activity}

Anti-inflammatory activity was assessed by a method previously described [24]. In brief, extracts were re-dissolved and diluted in distilled water to concentrations that ranged from 6.25 to $400 \mu \mathrm{g} / \mathrm{mL}$. Griess Reagent System (GRS) kit was applied to measure the nitric oxide using a mouse macrophage-like cell line RAW 264.7. The final absorption was read at $515 \mathrm{~nm}$ using an ELx800 microplate reader (Bio-Tek Instruments, Inc; Winooski, VT, USA). The final results were expressed as $\mathrm{IC}_{50}$ values. Dexamethasone (Dex) was used as a positive control, while the negative control contained no bacterial lipopolysaccharides (LPS).

\subsection{Inhibition of Fungal $\alpha$-Glucosidase}

Inhibition of fungal $\alpha$-glucosidase (AGLU) was carried out by a method described by Sakna et al. (2019) [29] with slight modifications. In brief, fifty microliters of extract solution (sequential dilutions) and fifty microliters of the enzyme solution (at a concentration of $2 \mathrm{U} / \mathrm{mL})$ diluted in phosphate buffer $(0.1 \mathrm{M}, \mathrm{pH} 6.8)$ were mixed in a 96-well plate and incubated in a place protected from light at a temperature of $37^{\circ} \mathrm{C}$. After $10 \mathrm{~min}, 50 \mu \mathrm{L}$ of $\alpha$-pNPG solution ( $2.5 \mathrm{mM})$, also prepared in phosphate buffer $(0.1 \mathrm{M}, \mathrm{pH} 6.8)$, were added to the mixture and incubated at $37^{\circ} \mathrm{C}$, in a place protected from light. After another $10 \mathrm{~min}$, the absorbance was measured at $405 \mathrm{~nm}$ spectrophotometrically.

AGLU activity was calculated according to the following formula:

$$
\text { Inhibition }(\%)=\frac{(\mathrm{A}-\mathrm{B})-(\mathrm{C}-\mathrm{D})}{(\mathrm{A}-\mathrm{B})} \times 100
$$

where $\mathrm{A}$ is the absorbance of the control and B is the absorbance of the blank control. C and $\mathrm{D}$ are the absorbances of the sample and blank sample. The $\alpha$-glucosidase inhibitory activity was expressed as an $\mathrm{IC}_{50}$ value.

\subsection{Rat $\alpha$-Glucosidase Inhibitory Assay}

For the rat $\alpha$-glucosidase inhibitory assay, rat intestinal acetone powder dissolved in phosphate buffer $(0.1 \mathrm{M}, \mathrm{pH}$ 6.9) at a ratio of 50:1 (w:v), was centrifuged for $10 \mathrm{~min}$ (4000 rpm). Enzyme solution for rat $\alpha$-glucosidase inhibition was prepared using a five-fold diluted supernatant with phosphate buffer, the rest of the assay procedure being performed in the same method as that for the inhibition of fungal $\alpha$-glucosidase [29]. 


\subsection{Statistical Analysis}

The experiments were carried out in triplicate and the data are expressed as mean values \pm SD for each sample. Moreover, data were evaluated by one-way analysis of variance in order to identify significant differences between values. Differences described by a $p$ value of $<0.05$ were considered significant. The statistical significance of differences and the statistical correlation between data were calculated using SPSS 16.0 (Armonk, NY, USA) for Windows.

\section{Results and Discussion}

\subsection{Drying Process Optimization}

The drying process of plant materials was analyzed and optimized using a specialized software, MODDE Pro, v. 11.0. The temperature of the air flow plays a crucial role in the process, as its increase or decrease can lower or higher the drying time, respectively, as can be seen in Figures 1 and 2. On the other hand, it is well known that the temperature can alter the structure of certain plant bioactive compounds [30]. Hence, given these implications, the drying temperature was lowered so that a lower amount of bioactive compounds would be destroyed. However, as the scope of this research was to extend the process to an industrial scale, we needed to find a balance between the temperature and the time required for the whole process. Consequently, the optimal temperature considered was $60^{\circ} \mathrm{C}$. The drying parameters were integrated into the software and the optimal time of fruit dried at $60^{\circ} \mathrm{C}$ was calculated.

Based on the developed experimental model, the optimal time required for drying the barberry fruits (B. vulgaris) at $60^{\circ} \mathrm{C}$ was calculated and it was found to be $14.328 \mathrm{~h}$. Previous studies on barberry fruit demonstrated that the air velocity had no major effect on the quality of the dried fruits, whereas the air temperature significantly affected Hunter color values [31]. The same team investigated the dehydration kinetics of barberry at different drying temperatures. They concluded that the use of low temperatures (e.g., $60{ }^{\circ} \mathrm{C}$ ) is adequate for preserving the color of the dried fruits, and a fruit pre-treatment with olive oil and $\mathrm{K}_{2} \mathrm{CO}_{3}$ reduced the drying time by $40 \%$ and $60 \%$, respectively. These results can be further integrated in a study to compare the composition and biological activity of the pretreated fruits versus simple-dried fruits. Another research team investigated the influence of harvesting methods (branch-cutting, cluster picking, and impact force), time of harvest, and drying methods on quality of dried fruits [32]. They concluded that the highest quality of dried fruits was obtained for those that were harvested by the clusterpicking method and shade-dried in late October. These results are in accordance with those obtained by [2]. They documented that the quality of fruit dried in direct sunlight is lower than those dried in mechanical dryers in terms of preserving their natural color and shape. The authors of [33] also concluded in their study that the greatest drying rate in the shortest time $\left(0.1332 \mathrm{~kg}\right.$ moisture $/ \mathrm{kg}$ dry matter) was associated with the samples dried at $55^{\circ} \mathrm{C}$ with citric acid pre-treatment.

All these conclusions are in accordance with the results obtained in this study. The samples were evaluated in terms of TFC. As can be seen in Figure 3, the highest amount of flavonoids corresponding to $\sim 14 \mathrm{~h}$ of drying was found for the fruits dried at $60{ }^{\circ} \mathrm{C}$. Furthermore, the results from the evaluation of total phenolic content (TPC) of the $14 \mathrm{~h}$ - dried berries revealed that those dried at $60{ }^{\circ} \mathrm{C}$ were the richest in these compounds (Figure 3) The antioxidant activity can also be correlated with the content of flavonoids and phenolic compounds, with the fruits dried at $60{ }^{\circ} \mathrm{C}$ exerting the highest antioxidant capacity (Figure 3). It can be concluded that the ideal temperature for barberry fruit drying is $60^{\circ} \mathrm{C}$. The optimal drying time at $60^{\circ} \mathrm{C}$ of $\mathrm{C}$. monogyna fruits was $16.1437 \mathrm{~h}$. Koyuncu et al. (2007) evaluated the influence of air temperature on total drying time and total energy requirement [34]. Although the drying parameters were not correlated with any in vivo or in vitro activity of the resultant samples, the authors concluded that the most economic method regarding energy consumption was obtained by drying the fruits at $70{ }^{\circ} \mathrm{C}$. On the other hand, Unal and Sacilik (2011) concluded that the total color change was reduced by 
decreasing the drying time, and this can be considered a quality parameter of the dried fruits [35]. At this moment, there are not enough data on the correlation between the drying parameters of $C$. monogyna fruits and their biologically active compounds content. The authors of the present study expect that the results presented here may lead to further investigations of the described dried fruits.

A

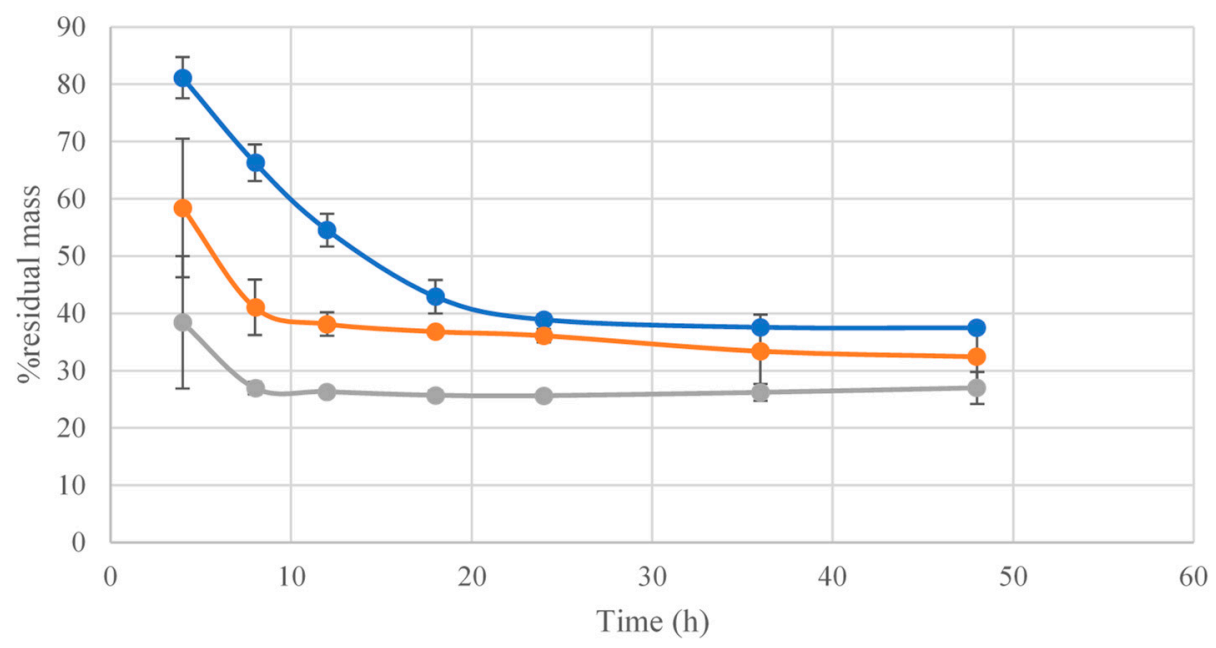

$\longrightarrow 50^{\circ} \mathrm{C} \longrightarrow 60^{\circ} \mathrm{C} \longrightarrow 70^{\circ} \mathrm{C}$

B

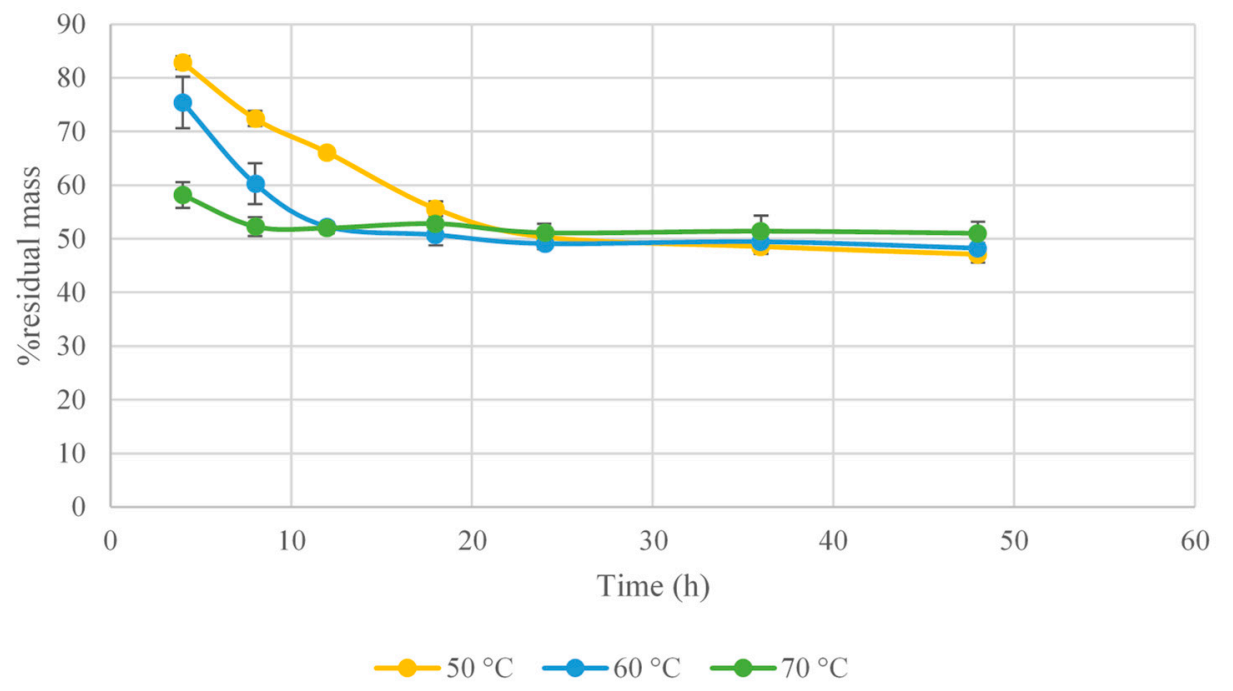

Figure 1. Residual mass percentage versus drying time for temperatures of 50,60 , and $70{ }^{\circ} \mathrm{C}$ in B. vulagris (A) and C. monogyna (B). 
A

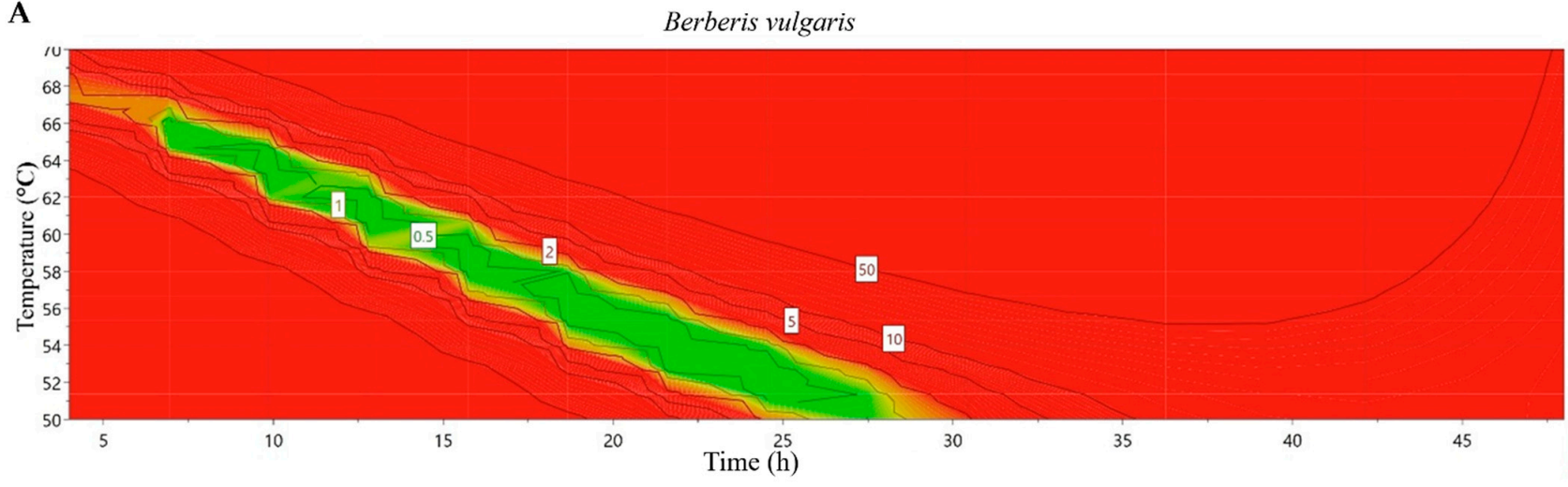

Crataegus monogyna
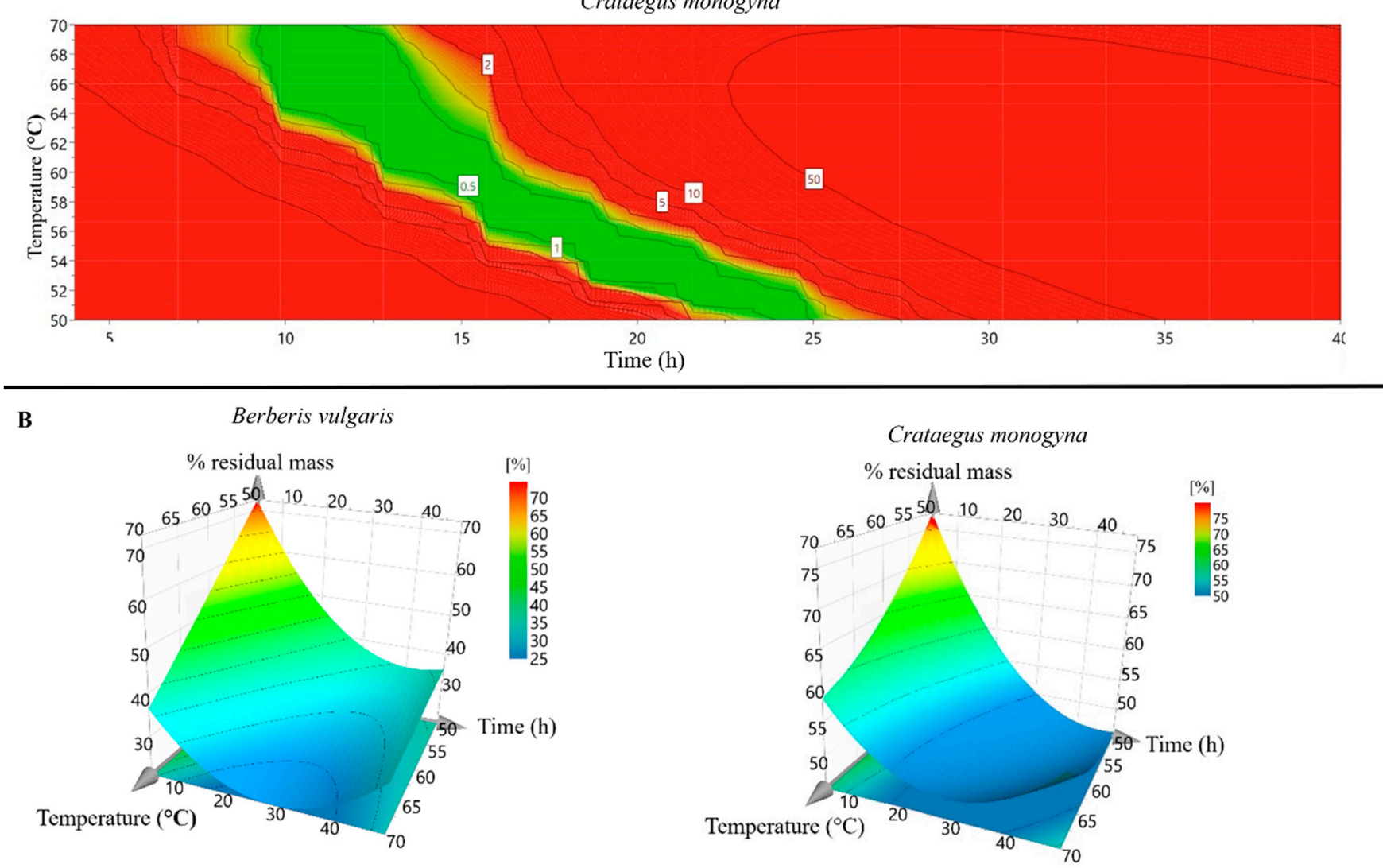

Figure 2. (A) Optimal temperature conditions represented in design spaces as a function of time for drying processes, (B) 3D-response surface plots: The interdependence between critical drying process parameters (temperature and time of drying) with the percent of residual mass for B. vulgaris and C. monogyna samples.

According to the preliminary results of the dried fruits after $\sim 16 \mathrm{~h}$ of drying, the highest total flavonoid content was obtained for those dried at $70^{\circ} \mathrm{C}$, followed by the fruits dried at $60^{\circ} \mathrm{C}$ (Figure 3). On the other hand, the fruits dried at $60^{\circ} \mathrm{C}$ exerted the highest total phenolic content (TPC), which correlates with the highest antioxidant capacity of the extracts. These results suggest that the optimal drying conditions are $\sim 16 \mathrm{~h}$ of drying at $60{ }^{\circ} \mathrm{C}$ air temperature. 
Berberis vulgaris L.

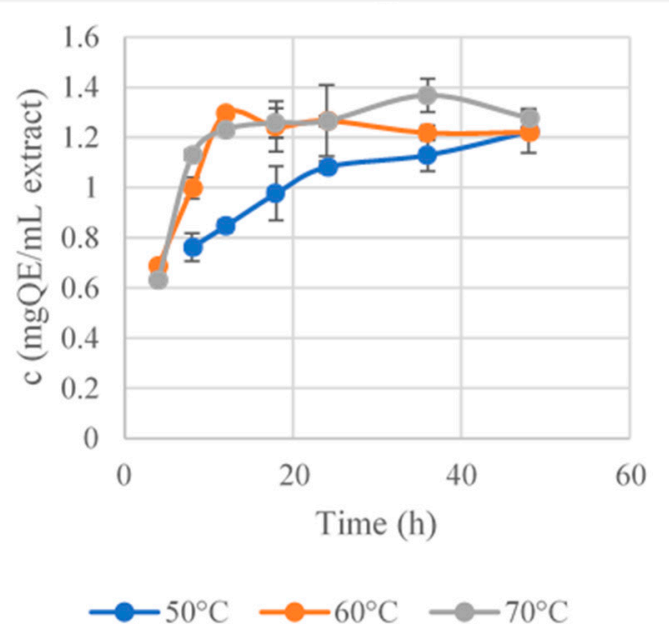

Crataegus monogyna Jacq.

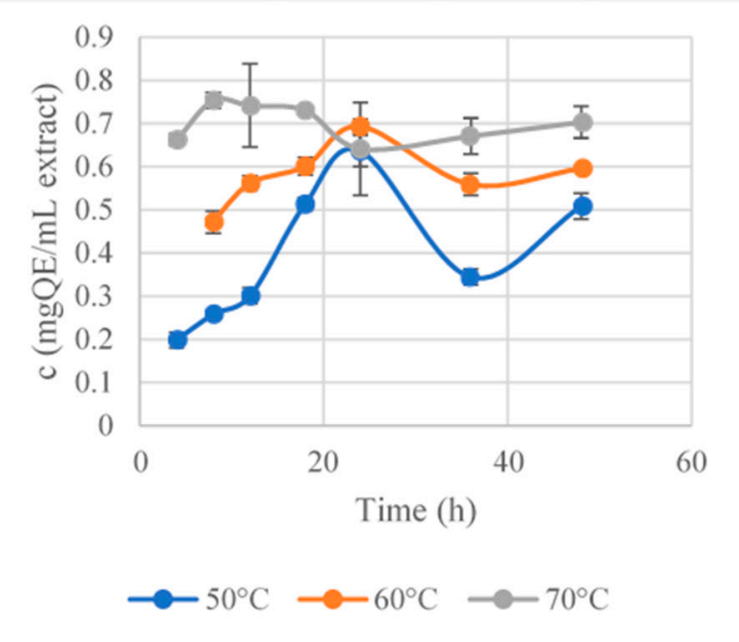

Total Flavonoid Content (TFC)
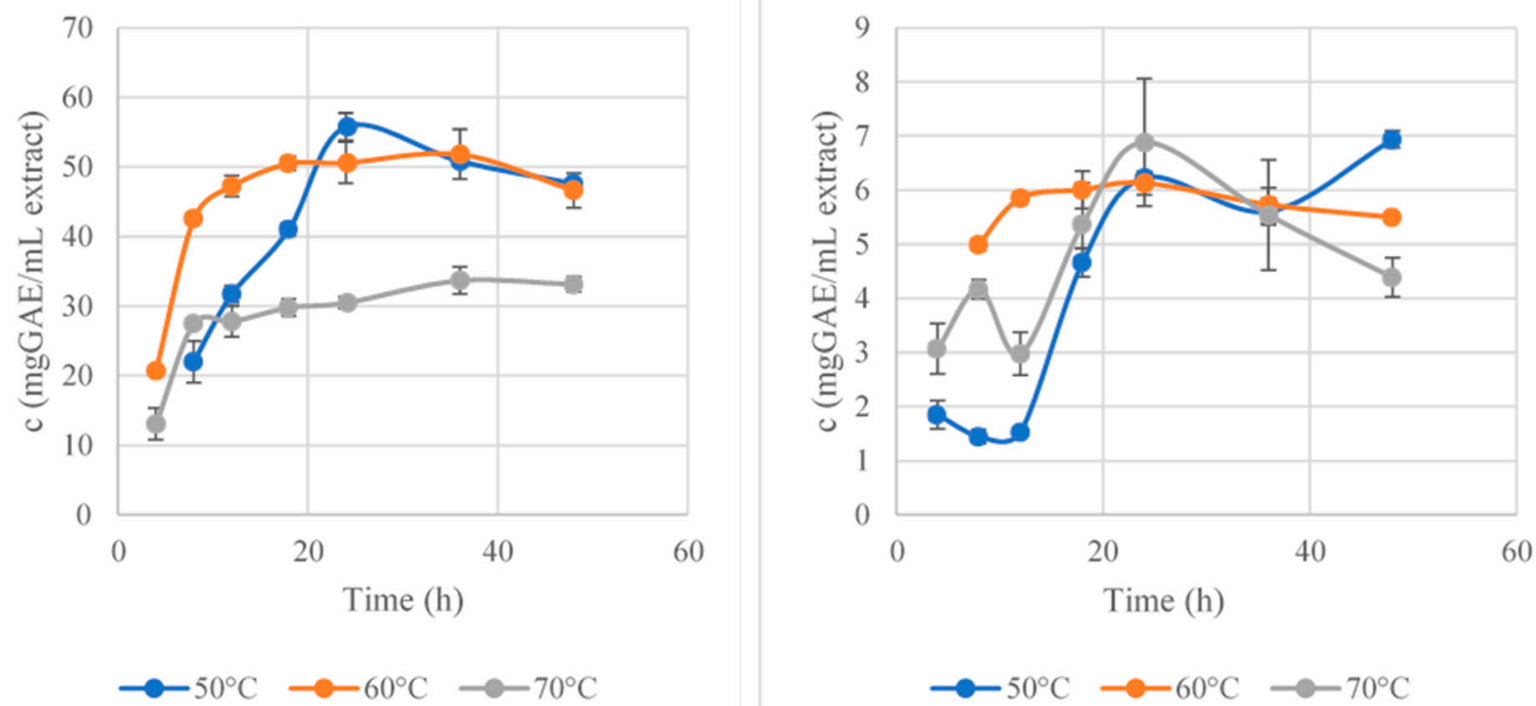

$\longrightarrow 50^{\circ} \mathrm{C} \longrightarrow 60^{\circ} \mathrm{C} \longrightarrow 70^{\circ} \mathrm{C}$

Total Phenolic Content (TPC)
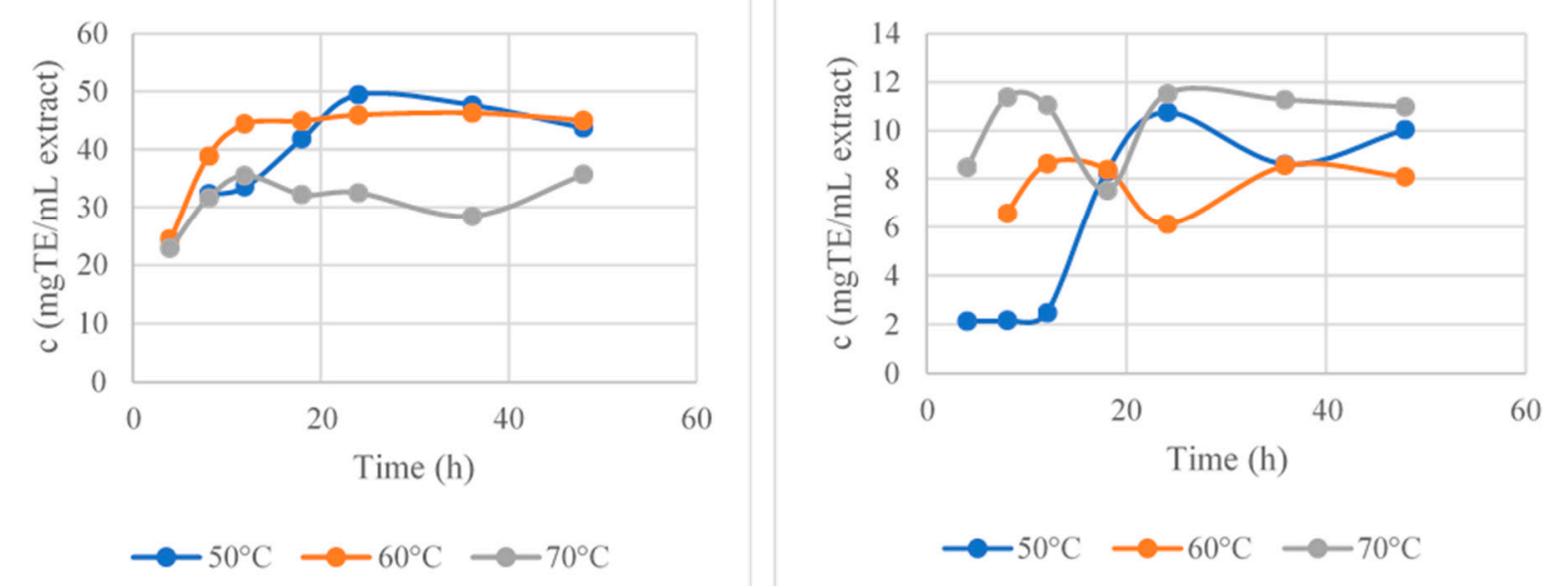

\section{DPPH radical scavenging activity}

Figure 3. Total phenolic content (TPC), total flavonoid content (TFC), and DPPH radical scavenging activity as a function of time regarding the temperature conditions of drying plant samples $\left(50,60\right.$, and $\left.70^{\circ} \mathrm{C}\right)$. 


\subsection{Phenolic Compounds Identification Using HPLC/MS}

Fifteen phenolic compounds where tentatively identified in the hydroethanolic extracts of B. vulgaris (peaks 1 to 8 ) and C. monogyna (peaks 9 to 15) (Table 1): seven flavonoids, five phenolic acids, two flavanonols, and one flavan-3-ol. A phenolic profile of both samples, recorded at $280 \mathrm{~nm}$ and $370 \mathrm{~nm}$, is presented in Figure 4.

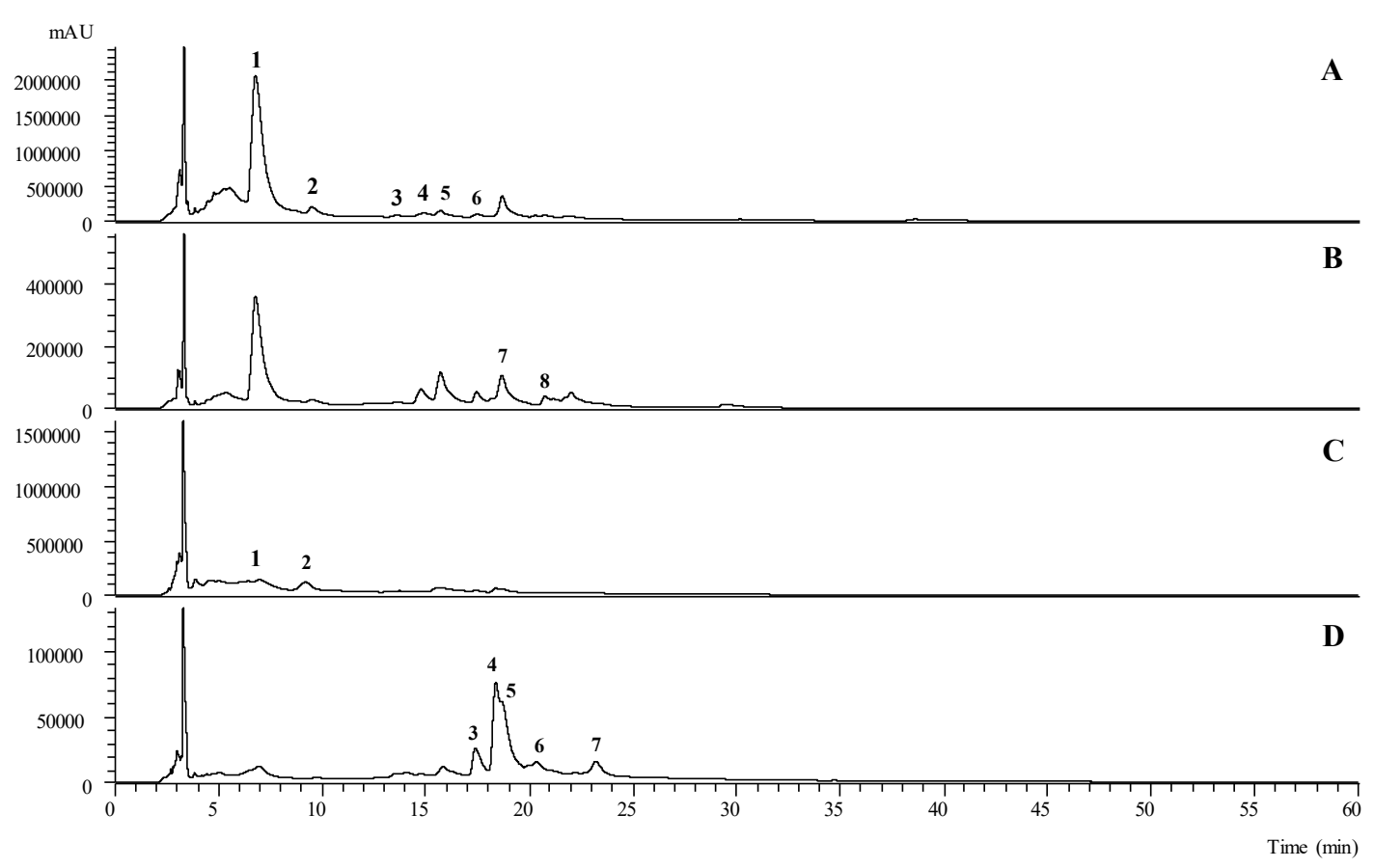

Figure 4. Chromatographic profile of B. vulgaris and C. monogyna recorded at $280 \mathrm{~nm}((\mathbf{A})$ and (C), respectively) and $370 \mathrm{~nm}$ ((B) and (D), respectively).

An O-glycosylated derivative of luteolin, peak $7\left([\mathrm{M}-\mathrm{H}]^{-}\right.$at $\left.m / z 593\right)$, with an a unique $\mathrm{MS}^{2}$ fragment at $m / z 285$ (luteolin aglycone), which corresponded to the loss of $176 \mathrm{u}$, tentatively identified as luteolin-O-glucuronide, was also identified in $B$. vulgaris samples. On the other hand, in C. monogyna samples a $C$-glycosilated derivative of apigenin was tentatively identified at peak 15 , presenting a pseudomolecular ion $[\mathrm{M}-\mathrm{H}]^{-}$at $m / z$ 619 and $\mathrm{MS}^{2}$ fragments at $m / z 499,413$, and 393, which was tentatively identified as apigenin 2"-O-rhamnosyl-C-acetylhexoside based on the description previously given by Barros et al. (2012) in the hydromethanolic extracts of $C$. monogyna from Northeastern Portugal [36].

The second largest family of compounds found was phenolic acids, being predominantly present in $B$. vulgaris samples, mainly as hydroxycinnamic acid derivatives. The fact that $B$. vulgaris samples presented a large number and variety of phenolic acids, mainly derived from hydroxycinnamic acids, is consistent with previously described findings by Fernández-Poyatos et al. (2021) on the leaves of Berberis hispanica Boiss. \& Reut. and Fernández-Poyatos et al. (2019) $[37,38]$ on the leaves of Berberis thunbergii DC. It is not surprising that one of these compounds is the major one found in B. vulgaris samples, representing $65 \%$ of the total amount of found phenolics (peak $1-34.1 \pm 0.6 \mathrm{mg} / \mathrm{g}$ extract). Peaks 1 and 2 presented a pseudomolecular ion $[\mathrm{M}-\mathrm{H}]^{-}$at $m / z 353, \mathrm{MS}^{2}$ fragments at $\mathrm{m} / \mathrm{z} 191,179,173$, and 135 , and a UV-vis spectra maximum of $324 / 325 \mathrm{~nm}$, consistent with caffeoylquinic acid derivatives. These numbers, elution orders, and fragment abundance are consistent with those previously described by Clifford et al. (2003), leading to their tentative identification as 3-O-caffeoylquinic acid (1) and 5-O-caffeoylquinic acid (2) [39]. Furthermore, peaks 5 and 6 presented a pseudomolecular ion $[\mathrm{M}-\mathrm{H}]^{-}$at $m / z 381$ and MS $^{2}$ fragments at $m / z 293,219,203,179,161$, and 135, which is in accordance with the fragment identification performed by Zhang et al. (2007) on Erigeron breviscapus extracts [40,41]. 
Due to a lack of information that could help us to identify the caffeoyl positions, 5 and 6 were tentatively identified as CDOA isomer I and II, respectively. The only phenolic acid compound found in C. monogyna was $p$-coumaric acid ([M - H $]^{-}$at $m / z 163$, peak 9), which was identified by comparison of its the retention time, UV-vis spectra, and mass fragmentation with the available standard compound.

Table 1. The retention time (Rt), wavelengths of maximum absorption $\left(\lambda_{\max }\right)$, tentative identification, mass spectral data, and quantification of phenolic compounds identified in the extracts of B. vulgaris and C. monogyna (Mean $\pm \mathrm{SD}$ ).

\begin{tabular}{|c|c|c|c|c|c|c|}
\hline Peak & $\begin{array}{c}\mathbf{R t} \\
(\mathrm{min})\end{array}$ & $\underset{(\mathrm{nm})}{\lambda \operatorname{Max}}$ & $\begin{array}{l}{[\mathbf{M}-\mathbf{H}]^{-}} \\
(\mathrm{m} / \mathrm{z})\end{array}$ & $\begin{array}{l}\mathrm{MS}^{2} \\
(\mathrm{~m} / \mathrm{z})\end{array}$ & Tentative Identification & $\begin{array}{l}\text { Quantification } \\
\text { (mg/g Extract) }\end{array}$ \\
\hline & & & & B. vulgaris & \multirow{9}{*}{$\begin{array}{c}\text { 3-O-Caffeoylquinic acid } \\
\text { 5-O-Caffeoylquinic acid } \\
\text { Hydroxy ampelopsin isomer } \\
\text { I } \\
\text { Hydroxy ampelopsin isomer } \\
\text { II } \\
\text { CDOA isomer I } \\
\text { CDOA isomer II } \\
\text { Luteolin-O-glucuronide } \\
\text { Quercetin-O-deoxyhexoside } \\
\text { Total phenolic compounds }\end{array}$} & \\
\hline $1^{\mathrm{G}}$ & 6.78 & 324 & 353 & $191(100), 179(51), 173(7), 135(5)$ & & $34.1 \pm 0.6$ \\
\hline $2^{\mathrm{G}}$ & 9.51 & 325 & 353 & $191(100), 179(11), 173(5), 135(5)$ & & $3.4 \pm 0.1$ \\
\hline $3^{\mathrm{F}}$ & 14.76 & 334 & 335 & $291(100), 273(12), 247(5), 229(10), 193(5), 179$ (15), 151 (5) & & $2.3 \pm 0.1$ \\
\hline $4^{\mathrm{F}}$ & 15.71 & 336 & 335 & 291 (100), 273 (12), 247 (5), $229(10), 193$ (5), 179 (15), $151(5)$ & & $1.68 \pm 0.01$ \\
\hline $5^{\mathrm{G}}$ & 17.45 & 332 & 381 & 293 (5), 219 (2), 203 (5), 179 (100), 161 (15), $135(21)$ & & $1.5724 \pm 0.03$ \\
\hline $6^{\mathrm{G}}$ & 18.66 & 328 & 381 & $293(5), 219(5), 203(5), 179(100), 161(9), 135(17)$ & & $4.55 \pm 0.05$ \\
\hline $7^{\mathrm{D}}$ & 20.75 & 330 & 593 & $285(100)$ & & $0.558 \pm 0.003$ \\
\hline $8^{\mathrm{D}}$ & 22.02 & 335 & 447 & $301(100)$ & & $\begin{array}{c}0.61 \pm 0.01 \\
49 \pm 1\end{array}$ \\
\hline \multicolumn{7}{|c|}{ C. monogyna } \\
\hline $9^{\mathrm{A}}$ & 6.99 & 310 & 163 & $119(100)$ & $p$-Coumaric acid & $0.1704 \pm 0.001$ \\
\hline $10^{\mathrm{B}}$ & 9.35 & 280 & 289 & 245 (100), 205 (29) & $(+)$-Catequin & $0.78 \pm 0.01$ \\
\hline $11^{\mathrm{C}}$ & 17.39 & 349 & 609 & $301(100)$ & Quercetin-3-O-rutinoside & $\operatorname{tr}$ \\
\hline $12^{\mathrm{D}}$ & 18.37 & 354 & 463 & $301(100)$ & Quercetin-3-O-glucoside & $0.202 \pm 0.004$ \\
\hline $13^{\mathrm{D}}$ & 18.66 & 352 & 463 & $301(100)$ & Quercetin-O-hexoside & $0.194 \pm 0.001$ \\
\hline $14^{\mathrm{D}}$ & 20.33 & 352 & 505 & 463 (100), $301(25)$ & Quercetin-O-acetylhexoside & $0.132 \pm 0.001$ \\
\hline \multirow[t]{2}{*}{$15^{\mathrm{E}}$} & 23.19 & 324 & 619 & 499 (5), $413(71), 393(100)$ & $\begin{array}{c}\text { Apigenin } 2 "-O \text {-rhamnosyl-C- } \\
\text { acetylhexoside }\end{array}$ & $0.088 \pm 0.001$ \\
\hline & & & & & Total phenolic compounds & $1.568 \pm 0.002$ \\
\hline
\end{tabular}

tr-traces. Standard calibration curves: A—p-coumaric acid $\left(y=301950 x+6966.7, R^{2}=0.9999, \mathrm{LOD}=0.68 \mu \mathrm{g} / \mathrm{mL} ; \mathrm{LOQ}=1.61 \mu \mathrm{g} / \mathrm{mL}\right)$; $\mathrm{B}$-(+)-catequin $\left(y=84950 x-23200, R^{2}=1, \mathrm{LOD}=0.17 \mu \mathrm{g} / \mathrm{mL} ; \mathrm{LOQ}=0.68 \mu \mathrm{g} / \mathrm{mL}\right) ; \mathrm{C}$-quercetin 3-O-rutinoside $(y=13343 x+76751$, $\left.R^{2}=0.9998, \mathrm{LOD}=0.18 \mu \mathrm{g} / \mathrm{mL} ; \mathrm{LOQ}=0.65 \mu \mathrm{g} / \mathrm{mL}\right) ; \mathrm{D}$-quercetin 3-O-glucoside $\left(y=34843 x-160173, R^{2}=0.9998, \mathrm{LOD} 0.21 \mu \mathrm{g} / \mathrm{mL} ;\right.$ LOQ $0.71 \mu \mathrm{g} / \mathrm{mL}) ; \mathrm{E}-$ Apigenin-6-C-glucoside $\left(y=107025 x+61531, R^{2}=0.9989, \mathrm{LOD}=0.19 \mu \mathrm{g} / \mathrm{mL} ; \mathrm{LOQ}=0.63 \mu \mathrm{g} / \mathrm{mL}\right) ; \mathrm{F}-$ naringenin $\left(y=18433 x+78903, R^{2}=0.9998, \mathrm{LOD}=0.17 \mu \mathrm{g} / \mathrm{mL} ; \mathrm{LOQ}=0.81 \mu \mathrm{g} / \mathrm{mL}\right) ; \mathrm{G}$-chlorogenic acid $\left(y=168823 x-161172, R^{2}=0.9999\right.$, $\mathrm{LOD}=0.20 \mu \mathrm{g} / \mathrm{mL} ; \mathrm{LOQ}=0.68 \mu \mathrm{g} / \mathrm{mL}$ ). CDOA-caffeoyl-2,7-anhydro-3-deoxy-2-octulopyranosonic acids.

The flavonoid family of compounds was the one that stood out the most in C. monogyna samples, with five compounds tentatively identified, which did not happen in B. vulgaris samples, with only two tentatively identified. O-glycosylated quercetin derivatives were the ones found in higher numbers. Peaks $11\left([\mathrm{M}-\mathrm{H}]^{-}\right.$at $\left.m / z 609\right)$ and $12\left([\mathrm{M}-\mathrm{H}]^{-}\right.$at $\left.m / z 463\right)$ were found to be quercetin-3-O-rutinoside and quercetin-3-O-glucoside, respectively, by comparing their retention time, UV-vis spectra, and mass fragmentation of available commercial standards. Peak $13\left([\mathrm{M}-\mathrm{H}]^{-}\right.$at $\left.m / z 463\right)$, presented the same chromatographic responses as peak 12, except for the retention time, which does not allow us to definitively identify the sugar moiety linked to the quercetin aglycone. It was thus tentatively identified as quercetin-O-hexoside. Peak $8\left([\mathrm{M}-\mathrm{H}]^{-}\right.$at $\left.m / z 447\right)$, which presented a unique $\mathrm{MS}^{2}$ fragment at $m / z 301$ corresponding to the loss of $146 \mathrm{u}$ (deoxyhexosyl moiety), was tentatively identified as quercetin-O-deoxyhexoside. Finally, peak 14 presented a pseudomolecular ion $[\mathrm{M}-\mathrm{H}]^{-}$at $m / z 505$ and two subsequent $\mathrm{MS}^{2}$ fragments at $m / z 463(42 \mathrm{u}$ ) and $m / z 301$ $(162 \mathrm{u})$ due to the loss of acetyl and hexosyl moieties, respectively, and was thus tentatively identified as quercetin- $O$-acetylhexoside.

Two flavanonols were tentatively identified in B. vulgaris samples, peaks 3 and 4 $\left([\mathrm{M}-\mathrm{H}]^{-}\right.$at $\left.m / z 335\right)$, that presented a fragmentation $\mathrm{MS}^{2}$ pattern consistent with that previously described by Kang et al. (2016) in the hydroethanolic extracts of sorghum wholegrains [42]. Finally, the only flavan-3-ol was identified (in C. monogyna samples), peak $10\left([\mathrm{M}-\mathrm{H}]^{-}\right.$at $\left.m / z 289\right)$, by comparison with the available standard compound in terms of retention time, UV-vis spectra, and mass fragmentation. Despite presenting with a lower concentration of total phenolic compounds than the B. vulgaris samples, the phenolic profile described for C. monogyna is consistent with the existing literature [43-45]. 


\subsection{Total Phenolic Content (TPC) and Total Flavonoid Content (TFC)}

The purpose of this research was to identify the optimum drying conditions for the extraction of the bioactive compounds from plant materials from B. vulgaris and C. monogyna.

The obtained results are presented in Table 2 and were compared with those from the literature related to bioactive compounds found in the composition of the studied plants' materials. Furthermore, a correlation between chemical composition and pharmacological effects of fruit extracts was realized in order to underline plants' utilities.

Table 2. Total phenolic content (TPC), total flavonoid content (TFC), and antioxidant activity.

\begin{tabular}{ccc}
\hline & C. monogyna & B. vulgaris \\
\hline TFC $(\mathrm{mg} \mathrm{QE} / \mathrm{g} \mathrm{dw})$ & $2.584 \pm 0.238$ & $8.306 \pm 0.509$ \\
TPC $(\mathrm{mg} \mathrm{GAE} / \mathrm{g} \mathrm{dw})$ & $23.371 \pm 1.178$ & $100.862 \pm 1.967$ \\
\hline DPPH $(\mathrm{mg} \mathrm{TE} / \mathrm{g} \mathrm{dw})$ & $34.343 \pm 1.025$ & $50.853 \pm 0.246$ \\
TEAC $(\mathrm{mg} \mathrm{TE} / \mathrm{g} \mathrm{dw})$ & $12.677 \pm 0.618$ & $30.983 \pm 0.649$ \\
FRAP $(\mathrm{mg} \mathrm{TE} / \mathrm{g} \mathrm{dw})$ & $74.341 \pm 2.229$ & $302.458 \pm 15.257$ \\
TBARS $(\mathrm{IC} 50 ; \mu \mathrm{g} / \mathrm{mL})^{1}$ & $72.2 \pm 0.9$ & $252.5 \pm 14.2$ \\
OxHLIA $\Delta \mathrm{t}=60 \mathrm{~min}\left(\mathrm{IC} \mathrm{C}_{50} ; \mu \mathrm{gg} / \mathrm{mL}\right)^{1}$ & $118 \pm 7$ & $76 \pm 1$ \\
\hline
\end{tabular}

Flavonoids are secondary plant metabolites with low molecular weights. They are phenolic compounds that can be found in either a free state or a glycosylated state. Due to their nature, the scientific literature documents the presence of a wide range of pharmacological actions with beneficial effects across all body systems (neuroprotective and anti-convulsive effects on the central nervous system, treatment and prevention of some particular cardiovascular diseases, treatment of dyslipidemia, etc.). Recent studies have shown that flavonoids are effective at targeting biological processes that affect the development of type 2 diabetes mellitus, inflammation, and immune system activity [46]. Besides the aforementioned effects, flavonoids pose antitumoral, antimicrobial, and antifungal activities [47].

A spectrophotometric assay based on aluminum-complex formation is one of the most applied methods for the quantification of TFC in food and medicinal plants. Although in the study of Pẹkal and Pyrzynska (2014) this method showed irregular interaction with all flavonoid compounds, we consider this a preliminary step towards investigating the composition of plants we wish to study in a more in-depth manner using modern techniques [48].

The extract obtained from dried barberry fruit (B. vulgaris) exerted a high value in terms of TFC (8.306 $\pm 0.509 \mathrm{mg} \mathrm{QE} / \mathrm{g} \mathrm{dw}$ extract). As far as we know, the inside of $B$. vulgaris fruits have not been assessed in terms of flavonoid content, so a comparison cannot be made.

Considering the C. monogyna extract, the value of $2.584 \pm 0.238 \mathrm{mg} \mathrm{QE} / \mathrm{g} \mathrm{dw}$ was similar to that obtained by [49] from C. monogyna species collected from the region of Valenciennes, Northern France (2.60-4.90 mg GAE/g dw). In their study, they deep-froze the fresh berries in order to preserve the bioactive constituents. Furthermore, the extraction procedure was slightly different from the one used in our study. The plant material was macerated for $24 \mathrm{~h}$ at $4{ }^{\circ} \mathrm{C}$ in a $500 \mathrm{~mL}$ methanol/water mixture $(30 / 70, v / v)$, followed by the selective extraction of compounds with dichloromethane. The authors of [50] also evaluated the TFC of the C. monogyna berries, collected from Chile. They obtained a higher value in terms of total flavonoids $(8.77 \mathrm{mgQE} / \mathrm{g} \mathrm{dw})$, which can be ascribed to the fact that the pulp of the fruits is richer in flavonoids than the whole pseudofruit. In a recent study, [51] evaluated the total flavonoid content of berries collected from Bragança, Northeastern Portugal. The value obtained varied from 21.70 to $436.34 \mathrm{mg}$ CE/g per extract. A comparison could not be made because of the different standards used. In Sarajevo, Bosnia and Herzegovina, [52] evaluated the flavonoid content of pseudofruits, 
which exerted 0.254-0.595 mg RUE/g of fresh fruits. Again, a comparison could not be made, due to the different means of result expression.

Secondary metabolites that are derivatives of the pentose phosphate, shikimate, and phenylpropanoid pathways in plants are known as phenolic compounds. Phenolic compounds are widely distributed in plants, playing important roles in their physiology and morphology. Their physiological properties are the main reason why phenolic compounds have been intensively studied in recent years. Among the most important physiological properties are their anti-allergenic, antioxidant, anti-inflammatory, anti-atherogenic, antimicrobial, anti-thrombotic, vasodilatory, and cardioprotective effects [53]. Although this approach has some drawbacks, we used the Folin-Ciocâlteu method to assess total phenolic content in fruits extracts because of its easy application [54].

B. vulgaris fruits extract was evaluated in terms of total phenolic content and the value obtained was $100.862 \pm 1.967 \mathrm{mg}$ GAE/g dw. Özgen et al. assessed the TPC of fresh fruits collected from Sivas province in Turkey [55]. The samples were processed right after the collecting, and the result ranged between 2565 and 3629 mg GAE per liter of fruit juice. Motalleb et al. obtained similar results for fruits collected from Malaysia (100 and $280 \mathrm{mg}$ GAE/g, for water and methanolic extract, respectively) [56]. They dried the plants at a temperature of $65^{\circ} \mathrm{C}$ for three days and extracted the chemical constituents in hot water for 20-30 min, followed by extraction in a water:ethanol mixture (1:10). The procedure was repeated twice, then the thick syrup obtained by evaporation in vacuum conditions was freeze-dried. The authors of [57] evaluated the phenolic content in barberry fruits collected from Khorasan province of Iran and obtained 184.1 and 291.22 mg GAE/g dw for aqueous and alcoholic extracts, respectively. The fruits were dried at room temperature in the dark. These results suggest that the temperature can exert a negative effect on chemical the composition of barberry fruits, especially on phenolic compounds. On the other hand, as stated before, the phenolic content was assessed using Folin-Ciocâlteu method. Barberry fruits are known due to their Vitamin C contents, and it is also known that a high temperature can deteriorate its structure. Thus, the lower TPC content can be ascribed to the limitation of the method used.

The total phenolic content was also evaluated for C. monogyna fruit extracts. The value ( $23.371 \pm 1.178 \mathrm{mg} \mathrm{GAE} / \mathrm{g}$ of dry weight extract) is comparable to those found in the scientific literature. The authors of [58] revealed that the extract of the fruits collected from C. monogyna and C. oxycantha, from Pomoravlje Province, Serbia contain $35.50 \pm 2.48 \mathrm{mg}$ GAE/g of extract. Furthermore, the extract from Chilean hawthorn pseudofruits exerted $28.30 \pm 0.02 \mathrm{mg}$ $\mathrm{GAE} / \mathrm{g}$ of extract. Another team from Tunisia evaluated the phenolic content of hawthorn pulp. They concluded that the content in phenolics ranged between 2.2756 and $14.61 \mathrm{mg}$ GAE/g fw [59]. A similar result was obtained by another team from Bosnia and Herzegovina, who concluded that the extract's phenolics from hawthorn fruits ranged between 2.01 and $4.60 \mathrm{mg} \mathrm{GAE} / \mathrm{g}$ of fresh fruit. These results suggest that the drying conditions and extraction method play a huge role in the output of these compounds.

\subsection{Antioxidant Activity}

The DPPH assay is widely used to analyze antioxidant activity of plants' extracts by measuring the extract's ability to scavenge DPPH radicals and therefore determine free radical scavenging capacity (Table 2). Extract of fruits of B. vulgaris exhibited a high antioxidant capacity against DPPH radicals $(50.853 \pm 0.246 \mathrm{mg}$ TE/g of lyophilized extract). In a study conducted by Motalleb et al., aqueous and ethanolic extracts of barberry exerted an inhibitory concentration value at which the DPPH radical is scavenged by $50 \%\left(\mathrm{IC}_{50}\right)$ of $0.65 \mathrm{mg} / \mathrm{mL}$ [56]. Furthermore, the DPPH radical scavenging activity of an extract obtained through an optimized process was able to inhibit $91.15 \%$ of radicals [60].

The TEAC assay is also extensively employed to assess total radical scavenging capacity. This assay assesses the ability of antioxidants to scavenge the radical cation $\mathrm{ABTS}^{\bullet+}$. The total antioxidant activity of lyophilized extracts of barberry assessed by TEAC 
was $30.983 \pm 0.649 \mathrm{mg}$ TE/g dw (Table 2). Other research groups reported a TEAC value of $8.731 \pm 0.185 \mathrm{mmol} \mathrm{TE} / \mathrm{L}$ for barberry juice and 41.1-49.3 mmol TE/L for fruit juice [55,61].

Regarding C. monogyna, the DPPH radical scavenging activity of the lyophilized extract was $34.343 \pm 1.025 \mathrm{mg}$ TE/g. However, the scientific literature reports inconsistent results. Therefore, Tadic et al. analyzed the DPPH radical scavenging activity of two hawthorn species [58]. The extracts were obtained by percolation and the $\mathrm{IC}_{50}$ was $52.05 \mu \mathrm{g} / \mathrm{mL}$ [58]. Another research group from Chile reported a more potent DPPH radical scavenging activity of hawthorn. Methanolic extract exhibited a total antioxidant activity of $3.61 \pm 0.01 \mu \mathrm{g} / \mathrm{m}$. Regarding TEAC assay, hawthorn exerted a value of $12.677 \pm 0.618 \mathrm{mg}$ TE/g lyophilized extract (Table 2).

\subsection{Cytotoxic and Anti-Inflammatory Activity}

Supplementary Table S1 presents the results of the cytotoxic activity of tested extracts based on normal and malignant cell line application. Interestingly, our extracts did not show any cytotoxic activity, either on normal, nor on cancerous cell lines.

In recent years, medical scientific research has focused on finding different pharmacological and botanical treatments for cancerous pathologies. This kind of research is focused on treatments with no side effects. Therefore, natural products are in the view of researchers due to their origin and their tendency to provide no serious side effects. Thus, the extracts of Berberis have shown great potential in this direction by reporting antitumor effects.

Hanachi et al. reported that barberry extract induced apoptosis in cancerous hepatic cells in rats [62]. Moreover, the B. vulgaris extract inhibited hepatic carcinogenesis in an animal model of disease [63]. The aqueous and ethanolic extracts of barberry also inhibited the proliferation of MCF-7 breast cancer cell line, but they had no effect on MCF10-A human breast epithelial cell line [57].

In a study published in 2008 by Tadic et al., researchers found that hawthorn fruit extract has a dose-dependent effect of reducing rat oedema induced by carrageenan. The extract was obtained by percolation of the C. monogyna and C. oxycantha fruits with $70 \%$ ethanol at room temperature [58].

\subsection{Inhibition of Fungal and Mammalian $\alpha$-Glucosidase}

For dietary carbohydrates to be digested, the presence of $\alpha$-glucosidase in the small intestine is of particular importance. Inhibitors are molecules that retard carbohydrate digestion, therefore suppressing glucose absorption and postprandial hyperglycemia [64]. Due to the capacity of some natural compounds from plant sources to inhibit $\alpha$-glucosidase, the importance of the assays examining the relation between compounds' capacity to inhibit $\alpha$-glucosidase and enzyme activity is well known. Table 3 presents our study data pertaining to the inhibitory activity of $\alpha$-glucosidase. Figure 5 presents the logarithm of extract concentration $[\mathrm{mg} / \mathrm{mL}]$ as a function of $\% \mathrm{I}$ (percent of enzyme inhibition).

Table 3. Inhibitory activity against fungal and mammalian $\alpha$-glucosidase of optimized extracts.

\begin{tabular}{ccc}
\hline & $\alpha$-Glucosidase Inhibitory Capacity \\
\hline Fungal $\left(\mathrm{IC}_{50} ; \mathrm{mg} / \mathrm{mL}\right)$ & $0.34 \pm 0.01$ & $0.56 \pm 0.02$ \\
Mammalian $(\% \mathrm{I} ; 8 \mathrm{mg} / \mathrm{mL})$ & na & na \\
\hline na-not active. & &
\end{tabular}
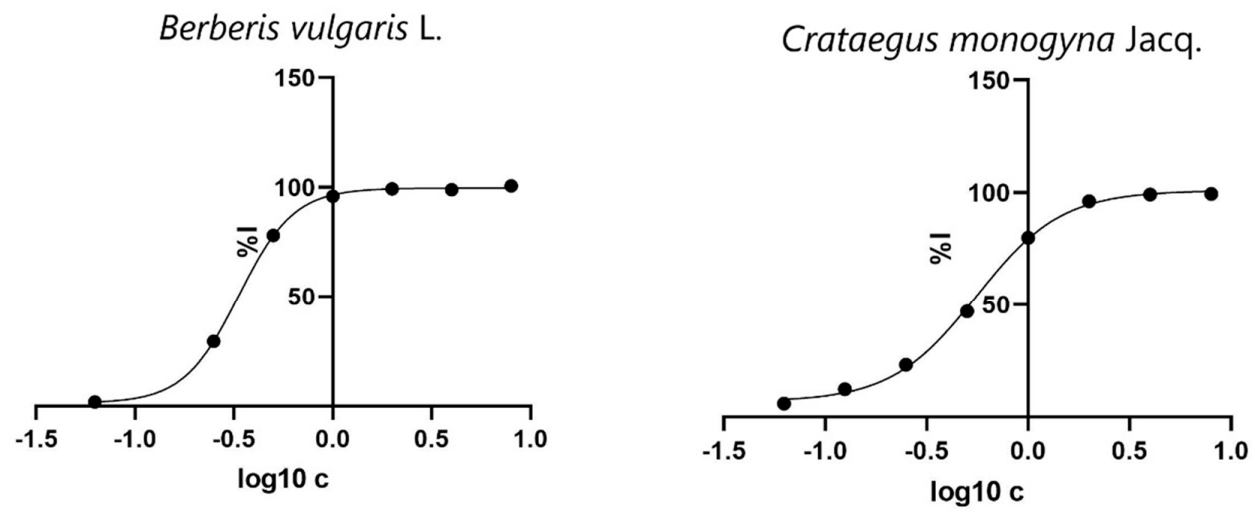
Hajzadeh et al. have shown that the maceration of Berberis fruits for $3 \mathrm{~h}$ followed by extraction did not have any effect on the lipidic profile of studied animals. Barberry extracts with a concentration of $3.5 \%$ and $7.5 \%$, administered for six weeks, presented no hypoglycemic or hypolipidemic effects in rats with streptozotocin induced diabetes [65].

Some in vivo studies have demonstrated that barberry fruit extract has no effect on glucose profile. However, studies have reported inconsistent data. Some researchers have mentioned a beneficial effect of $B$. vulgaris against diabetes and its subsequent pathophysiological effects $[65,66]$. Moreover, following the beneficial effect of barberry on diabetic markers, researchers were interested in studying the mechanisms by which fruits exert their antidiabetic effect. Two clinical studies identified potential explanations for the aforementioned effect. The first stated that a barberry extract obtained by fruit infusion has a beneficial effect on lipoprotein and apoprotein levels and could control glycemic levels of patients [67]. The second stated that barberry fruit extract could improve glucose catabolism (by supporting aerobe glycolysis), insulin secretion, and its action, but that it may also act on glucose absorption [68].

\section{Conclusions}

The drying of medicinal edible plant materials is a process that consists of various physical, chemical, and biological phenomena. It is very important to understand them in order to achieve high yields of bioactive compounds. In this paper, the drying process of two edible fruits traditionally used as remedies in Romania (i.e., B. vulgaris and C. monogyna) was optimized using an experimental design. It was found that the optimal time for drying $B$. vulgaris fruits at $60^{\circ} \mathrm{C}$ was $14.32 \mathrm{~h}$, whereas that for $C$. monogyna fruits at the same temperature was $16.14 \mathrm{~h}$. Furthermore, the extracts obtained by applying optimal drying conditions yielded high antioxidant activity (barberry fruits-50.85, 30.98, and $302.45 \mathrm{mg}$ TE/g dw for DPPH, TEAC, and FRAP assays, respectively). Moreover, $B$. vulgaris and C. monogyna extracts exhibited outstanding $\alpha$-glucosidase inhibitory activity $\left(\mathrm{IC}_{50}=0.34\right.$ and $0.56 \mathrm{mg} / \mathrm{mL}$, respectively). In the light of these results, the main bioactive phenolic compounds, mainly derived from hydroxycinnamic acids, were identified and quantified. Last but not least, industry could benefit from implementing this process, but more studies are needed to deeply understand the phenomena involved in the drying process of studied plant materials.

Supplementary Materials: The following are available online at https:/ / www.mdpi.com/article/ 10.3390/antiox10101579/s1, Table S1: Cytotoxic, anti-inflammatory, and inhibitory activity against fungal and mammalian $\alpha$-glucosidase of optimized extracts.

Author Contributions: Conceptualization, A.M. and L.M.; data curation, O.F., M.B., M.I.D. and A.M.; formal analysis, C.M., O.F., C.P. and L.B.; funding acquisition, A.M.; investigation, L.M., A.G. and C.T.; methodology, M.B., S.C., A.G., C.R.S., C.T., M.I.D., C.P., I.C.F.R.F. and A.M.; project administration, G.C. and A.M.; resources, A.M.; supervision, A.M.; writing—original draft, O.F., M.B., A.M. and L.B.; writing—review \& editing, C.M., L.M., S.C., A.G., C.T., M.I.D., I.C.F.R.F., G.C., A.M. and L.B. All authors have read and agreed to the published version of the manuscript.

Funding: This work was supported by a grant of the Romanian Ministry of Education and Research, CNCS-UEFISCDI, project number PN-III-P2-2.1-PED-2019-5360.

Institutional Review Board Statement: Not applicable.

Informed Consent Statement: Not applicable.

Data Availability Statement: Data are contained within the article or Supplementary Materials.

Acknowledgments: The authors are grateful to the Foundation for Science and Technology (FCT; Portugal) for financial support through national funds FCT /MCTES to CIMO (UIDB/00690/2020), the national funding for F.C.T. and P.I. and through the institutional scientific employment program contract for M.I.D. and L.B. The authors are grateful to FEDER-Interreg España-Portugal programme for financial support through the project TRANSCoLAB 0612_TRANS_CO_LAB_2_P. 
Conflicts of Interest: There are no conflicts of interest to declare.

\section{References}

1. Shikov, A.N.; Tsitsilin, A.N.; Pozharitskaya, O.N.; Makarov, V.G.; Heinrich, M. Traditional and current food use of wild plants listed in the Russian Pharmacopoeia. Front. Pharmacol. 2017, 8. [CrossRef]

2. Aghbashlo, M.; Kianmehr, M.H.; Samimi-Akhijahani, H. Influence of drying conditions on the effective moisture diffusivity, energy of activation and energy consumption during the thin-layer drying of berberis fruit (Berberidaceae). Energy Convers. Manag. 2008, 49, 2865-2871. [CrossRef]

3. Wang, W.; Yan, Z.; Yao, H.; Li, P.; Peng, W.; Su, W.; Wang, Y. Extraction and purification of pedunculoside from the dried barks of Ilex rotunda using crystallization combined with polyamide column chromatography. Sep. Sci. Technol. 2021, 56, 1710-1720. [CrossRef]

4. Mounir, S.; Mujumdar, A.S.; Bhandari, B.; Fang, Z. Advances in drying science and technology. In Handbook of Drying of Vegetables and Vegetable Products; CRC Press: Boca Raton, FL, USA, 2017.

5. Gavrilas, L.I.; Ionescu, C.; Bălăcescu, O.; Mureșan, D.; Revnic, C.; Filip, L.; Miere, D. Intake of plant based foods and colorectal cancer. A case-control study in Romania. Bull. Univ. Agric. Sci. Vet. Med. Cluj-Napoca. Food Sci. Technol. 2018, 75, 163. [CrossRef]

6. Saeed, N.; Khan, M.R.; Shabbir, M. Antioxidant activity, total phenolic and total flavonoid contents of whole plant extracts Torilis leptophylla L. BMC Complement. Altern. Med. 2012, 12. [CrossRef] [PubMed]

7. Kolosova, V.; Svanberg, I.; Kalle, R.; Strecker, L.; Özkan, A.M.G.; Pieroni, A.; Cianfaglione, K.; Molnár, Z.; Papp, N.; Łuczaj, Ł.; et al. The bear in Eurasian plant names: Motivations and models. J. Ethnobiol. Ethnomed. 2017, 13, 1-72. [CrossRef]

8. Javadzadeh, S.M.; Fallah, S.R. Therapeutic application of different parts Berberis vulgaris. Int. J. Agric. Crop Sci. 2012, 4, 404-408.

9. Neag, M.A.; Mocan, A.; Echeverría, J.; Pop, R.M.; Bocsan, C.I.; Crisan, G.; Buzoianu, A.D. Berberine: Botanical occurrence, traditional uses, extraction methods, and relevance in cardiovascular, metabolic, hepatic, and renal disorders. Front. Pharmacol. 2018, 9, 1-30. [CrossRef] [PubMed]

10. Rahimi-Madiseh, M.; Lorigoini, Z.; Zamani-Gharaghoshi, H.; Rafieian-Kopaei, M. Berberis vulgaris: Specifications and traditional uses. Iran. J. Basic Med. Sci. 2017, 20, 569-587. [CrossRef] [PubMed]

11. Minaiyan, M.; Ghannadi, A.; Mahzouni, P.; Jaffari-Shirazi, E. Comparative study of Berberis vulgaris fruit extract and berberine chloride effects on acetic acid-induced colitis in rats. Iran. J. Pharm. Res. 2011, 10, 97-104.

12. Tomosaka, H.; Young-Won, C.; Salim, A.A.; Keller, W.J.; Chai, H.; Kinghorn, C.D. Antioxidant and cytoprotective compounds from Berberis vulgaris (Barberry). Phyther. Res. 2008. [CrossRef]

13. Edwards, J.E.; Brown, P.N.; Talent, N.; Dickinson, T.A.; Shipley, P.R. A review of the chemistry of the genus Crataegus. Phytochemistry 2012, 79, 5-26. [CrossRef] [PubMed]

14. Nabavi, S.F.; Habtemariam, S.; Ahmed, T.; Sureda, A.; Daglia, M.; Sobarzo-Sánchez, E.; Nabavi, S.M. Polyphenolic composition of Crataegus monogyna Jacq.: From chemistry to medical applications. Nutrients 2015, 7, 7708-7728. [CrossRef] [PubMed]

15. Chang, Q.; Zuo, Z.; Harrison, F.; Sing, M.; Chow, S. Hawthorn. J. Clin. Pharmacol. 2002, 42, 605-612. [CrossRef]

16. Hawthorn berries Crataegi fructus. In European Pharmacopoeia; 2019. Available online: https://www.edqm.eu/en/europeanpharmacopoeia-ph-eur-10th-edition (accessed on 1 September 2021).

17. Sticher, O.; Meier, B. Hawthorn (Crataegus): Biological activity and new strategies for quality control. Phytomed. Eur. 2009, 241-262. [CrossRef]

18. Bessada, S.M.F.; Barreira, J.C.M.; Barros, L.; Ferreira, I.C.F.R.; Oliveira, M.B.P.P. Phenolic profile and antioxidant activity of Coleostephus myconis (L.) Rchb. f.: An underexploited and highly disseminated species. Ind. Crop. Prod. 2016, 89, 45-51. [CrossRef]

19. Mocan, A.; Zengin, G.; Crişan, G.; Mollica, A. Enzymatic assays and molecular modeling studies of Schisandra chinensis lignans and phenolics from fruit and leaf extracts. J. Enzyme Inhib. Med. Chem. 2016, 31, 200-210. [CrossRef] [PubMed]

20. Mocan, A.; Zengin, G.; Simirgiotis, M.; Schafberg, M.; Mollica, A.; Vodnar, D.C.; Crişan, G.; Rohn, S. Functional constituents of wild and cultivated Goji (L. barbarum L.) leaves: Phytochemical characterization, biological profile, and computational studies. J. Enzyme Inhib. Med. Chem. 2017, 32, 153-168. [CrossRef] [PubMed]

21. Moldovan, C.; Babota, M.; Mocan, A.; Menghini, L.; Cesa, S.; Gavan, A.; Sisea, C.; Vodnar, D.C.; Dias, M.I.; Pereira, C.; et al. Optimization of the drying process of autumn fruits rich in antioxidants: A study focusing on rosehip (Rosa canina L.) and sea buckthorn (Elaeagnus rhamnoides (L.) A. Nelson) and their bioactive properties. Food Funct. 2021, 12, 3939-3953. [CrossRef]

22. Mocan, A.; Crişan, G.; Vlase, L.; Crişan, O.; Vodnar, D.C.; Raita, O.; Gheldiu, A.M.; Toiu, A.; Oprean, R.; Tilea, I. Comparative studies on polyphenolic composition, antioxidant and antimicrobial activities of Schisandra chinensis leaves and fruits. Molecules 2014, 19, 15162-15179. [CrossRef]

23. Mocan, A.; Moldovan, C.; Zengin, G.; Bender, O.; Locatelli, M.; Simirgiotis, M.; Atalay, A.; Cristian, D.; Rohn, S.; Cri, G. UHPLC-QTOF-MS analysis of bioactive constituents from two Romanian goji (Lycium barbarum L.) berries cultivars and their antioxidant, enzyme inhibitory, and real-time cytotoxicological evaluation. Food Chem. Toxicol. 2018, 115, 414-424. [CrossRef] [PubMed]

24. Souilem, F.; Fernandes, Â.; Calhelha, R.C.; Barreira, J.C.M.; Barros, L.; Skhiri, F.; Martins, A.; Ferreira, I.C.F.R. Wild mushrooms and their mycelia as sources of bioactive compounds: Antioxidant, anti-inflammatory and cytotoxic properties. Food Chem. 2017, 230, 40-48. [CrossRef] [PubMed] 
25. Takebayashi, J.; Iwahashi, N.; Ishimi, Y.; Tai, A. Development of a simple 96-well plate method for evaluation of antioxidant activity based on the oxidative haemolysis inhibition assay (OxHLIA). Food Chem. 2012, 134, 606-610. [CrossRef]

26. Lockowandt, L.; Pinela, J.; Roriz, C.L.; Pereira, C.; Abreu, R.M.V.; Calhelha, R.C.; Alves, M.J.; Barros, L.; Bredol, M.; Ferreira, I.C.F.R. Chemical features and bioactivities of cornflower (Centaurea cyanus L.) capitula: The blue flowers and the unexplored non-edible part. Ind. Crops Prod. 2019, 128, 496-503. [CrossRef]

27. Abreu, R.M.V.; Ferreira, I.C.F.R.; Calhelha, R.C.; Lima, R.T.; Vasconcelos, M.H.; Adega, F.; Chaves, R.; Queiroz, M.-J.R.P. Anti-hepatocellular carcinoma activity using human HepG2 cells and hepatotoxicity of 6-substituted methyl 3-aminothieno [3,2-b]pyridine-2-carboxylate derivatives: In vitro evaluation, cell cycle analysis and QSAR studies. Eur. J. Med. Chem. 2011, 46, 5800-5806. [CrossRef]

28. Barros, L.; Pereira, E.; Calhelha, R.C.; Dueñas, M.; Carvalho, A.M.; Santos-Buelga, C.; Ferreira, I.C.F.R. Bioactivity and chemical characterization in hydrophilic and lipophilic compounds of Chenopodium ambrosioides L. J. Funct. Foods 2013, 5, 1732-1740. [CrossRef]

29. Sakna, S.T.; Mocan, A.; Sultani, H.N.; El-fiky, N.M.; Wessjohann, L.A.; Farag, M.A. Metabolites profiling of Ziziphus leaf taxa via UHPLC/PDA/ESI-MS in relation to their biological activities. Food Chem. 2019, 293, 233-246. [CrossRef]

30. Kamiloglu, S.; Toydemir, G.; Boyacioglu, D.; Beekwilder, J.; Hall, R.D.; Capanoglu, E. A review on the effect of drying on antioxidant potential of fruits and vegetables. Crit. Rev. Food Sci. Nutr. 2016, 56, S110-S129. [CrossRef]

31. Gorjian, S.; Tavakkoli Hashjin, T.; Khoshtaghaza, M.H.; Nikbakht, A.M. Drying kinetics and quality of barberry in a thin layer dryer. J. Agric. Sci. Technol. 2011, 13, 303-314.

32. Alavi, N.; Mazloumzadeh, S.M. Effect of harvesting and drying methods of seedless barberry on some fruit quality. J. Saudi Soc. Agric. Sci. 2012, 11, 51-55. [CrossRef]

33. Sharifi, A.; Hassani, B. Vacuum drying of barberry fruit (Berberis vulgaris) and selection of a suitable thin layer drying model. Res. J. Appl. Sci. Eng. Technol. 2013, 5, 1668-1673. [CrossRef]

34. Koyuncu, T.; Pinar, Y.; Lule, F. Convective drying characteristics of azarole red (Crataegus monogyna Jacq.) and yellow (Crataegus aronia Bosc.) fruits. J. Food Eng. 2007, 78, 1471-1475. [CrossRef]

35. Unal, H.G.; Sacilik, K. Drying characteristics of hawthorn fruits in a convective hot-air dryer. J. Food Process. Preserv. 2011, 35, 272-279. [CrossRef]

36. Barros, L.; Dueñas, M.; Carvalho, A.M.; Ferreira, I.C.F.R.; Santos-Buelga, C. Characterization of phenolic compounds in flowers of wild medicinal plants from Northeastern Portugal. Food Chem. Toxicol. 2012, 50, 1576-1582. [CrossRef]

37. Fernández-Poyatos, M.d.P.; Ruiz-Medina, A.; Salazar-Mendías, C.; Llorent-Martínez, E.J. Spectrophotometric determination of the antioxidant properties and characterization of the phenolic content by high-performance liquid chromatography-diode array detection-tandem mass spectrometry (HPLC-DAD-MS/MS) of Berberis hispanica Boiss. \& Reu. Anal. Lett. 2021, $54,646-657$. [CrossRef]

38. Fernández-Poyatos, M.d.P.F.-P.; Ruiz-Medina, A.; Zengin, G.; Llorent-Martínez, E.J. Phenolic characterization, antioxidant activity, and enzyme inhibitory properties of Berberis thunbergii DC. leaves: A valuable source of phenolic acids. Molecules 2019, $24,4171$. [CrossRef] [PubMed]

39. Clifford, M.N.; Johnston, K.L.; Knight, S.; Kuhnert, N. Hierarchical scheme for LC-MSn identification of chlorogenic acids. J. Agric. Food Chem. 2003, 51, 2900-2911. [CrossRef] [PubMed]

40. Zhang, Y.; Shi, P.; Qu, H.; Cheng, Y. Characterization of phenolic compounds in Erigeron breviscapus by liquid chromatography coupled to electrospray ionization mass spectrometry. Rapid Commun. Mass Spectrom. 2007, 21, 2971-2984. [CrossRef]

41. Zhang, J.M.; Guo, J.; Tu, X.; Shi, Z.H.; Hao, J.J.; Ke, Y.H.; Guan, J.F.; He, J.J. Protective effect of Huaxia shallot preparation on human umbilical vein endothelial injury induced by oxidized low density lipoprotein and its mechanism. J. Chinese Integr. Med. 2007, 5, 675-680. [CrossRef] [PubMed]

42. Kang, J.; Price, W.E.; Ashton, J.; Tapsell, L.C.; Johnson, S. Identification and characterization of phenolic compounds in hydromethanolic extracts of sorghum wholegrains by LC-ESI-MS(n). Food Chem. 2016, 211, 215-226. [CrossRef] [PubMed]

43. Liu, P.; Kallio, H.; Yang, B. Phenolic compounds in hawthorn (Crataegus grayana) fruits and leaves and changes during fruit ripening. J. Agric. Food Chem. 2011, 59, 11141-11149. [CrossRef]

44. Badalica-Petrescu, M.; Dragan, S.; Ranga, F.; Fetea, F.; Socaciu, C. Comparative HPLC-DAD-ESI(+)MS fingerprint and quantification of phenolic and flavonoid composition of aqueous leaf extracts of Cornus mas and Crataegus monogyna, in relation to their cardiotonic potential. Not. Bot. Horti Agrobot. Cluj-Napoca 2014, 42, 9-18. [CrossRef]

45. Rodrigues, S.; Calhelha, R.C.; Barreira, J.C.M.; Dueñas, M.; Carvalho, A.M.; Abreu, R.M.V.; Santos-Buelga, C.; Ferreira, I.C.F.R. Crataegus monogyna buds and fruits phenolic extracts: Growth inhibitory activity on human tumor cell lines and chemical characterization by HPLC-DAD-ESI/MS. Food Res. Int. 2012, 49, 516-523. [CrossRef]

46. Hussain, T.; Tan, B.; Murtaza, G.; Liu, G.; Rahu, N.; Saleem Kalhoro, M.; Hussain Kalhoro, D.; Adebowale, T.O.; Usman Mazhar, M.; ur Rehman, Z.; et al. Flavonoids and type 2 diabetes: Evidence of efficacy in clinical and animal studies and delivery strategies to enhance their therapeutic efficacy. Pharmacol. Res. 2020, 152, 104629. [CrossRef]

47. Romano, B.; Pagano, E.; Montanaro, V.; Fortunato, A.L.; Milic, N.; Borrelli, F. Novel insights into the pharmacology of flavonoids. Phyther. Res. 2013, 27, 1588-1596. [CrossRef] [PubMed]

48. Pękal, A.; Pyrzynska, K. Evaluation of aluminium complexation reaction for flavonoid content assay. Food Anal. Methods 2014, 7, 1776-1782. [CrossRef] 
49. Bahorun, T.; Trotin, F.; Pommery, J.; Vasseur, J.; Pinkas, M. Antioxidant activities of Crataegus monogyna extracts. Planta Med. 1994, 60, 323-328. [CrossRef] [PubMed]

50. Simirgiotis, M.J. Antioxidant capacity and HPLC-DAD-MS profiling of chilean peumo (Cryptocarya alba) fruits and comparison with german peumo (Crataegus monogyna) from Southern Chile. Molecules 2013, 18, 2061-2080. [CrossRef] [PubMed]

51. Barros, L.; Carvalho, A.M.; Ferreira, I.C.F.R. Comparing the composition and bioactivity of Crataegus monogyna flowers and fruits used in folk medicine. Phytochem. Anal. 2011, 22, 181-188. [CrossRef] [PubMed]

52. Tahirović, A.; Bašić, N. Phenolic content and antioxidant activity of Crataegus monogyna L. fruit extracts. Univ. Sarajev. 2014, 2, 29-40.

53. Balasundram, N.; Sundram, K.; Samman, S. Phenolic compounds in plants and agri-industrial by-products: Antioxidant activity, occurrence, and potential uses. Food Chem. 2006, 99, 191-203. [CrossRef]

54. Sánchez-Rangel, J.C.; Benavides, J.; Heredia, J.B.; Cisneros-Zevallos, L.; Jacobo-Velázquez, D.A. The Folin-Ciocalteu assay revisited: Improvement of its specificity for total phenolic content determination. Anal. Methods 2013, 5, 5990-5999. [CrossRef]

55. Özgen, M.; Saraçoğlu, O.; Geçer, E.N. Antioxidant capacity and chemical properties of selected barberry (Berberis vulgaris L.) fruits. Hortic. Environ. Biotechnol. 2012, 53, 447-451. [CrossRef]

56. Motalleb, G.; Hanachi, P.; Kua, S.H.; Fauziah, O.; Asmah, R. Evaluation of phenolic content and total antioxidant activity in Berberis vulgaris fruit extract. J. Biol. Sci. 2009, 5, 648-653. [CrossRef]

57. Hoshyar, R.; Mahboob, Z.; Zarban, A. The antioxidant and chemical properties of Berberis vulgaris and its cytotoxic effect on human breast carcinoma cells. Cytotechnology 2016, 68, 1207-1213. [CrossRef] [PubMed]

58. Tadic, V.M.; Dobric, S.; Marcovic, G.M.; Dordevic, S.M.; Arsic, I.A.; Menkovic, N.R.; Stevic, T. Anti-inflammatory, gastroprotective, free-radical-scavenging, and antimicrobial activities of hawthorn berries ethanol extract. J. Agric. Food Chem. 2008, 56, 7700-7709. [CrossRef] [PubMed]

59. Belkhir, M.; Rebai, O.; Dhaouadi, K.; Congiu, F.; Tuberoso, C.I.G.; Amri, M.; Fattouch, S. Comparative analysis of Tunisian wild Crataegus azarolus (yellow azarole) and Crataegus monogyna (red azarole) leaf, fruit, and traditionally derived syrup: Phenolic profiles and antioxidant and antimicrobial activities of the aqueous-aceton. J. Agric. Food Chem. 2013, 61, 9594-9601. [CrossRef] [PubMed]

60. Sharifi, A.; Mortazavi, S.A.; Maskooki, A.; Niakousari, M.; Elhamirad, A.H. Optimization of subcritical water extraction of bioactive compounds from barberry fruit (Berberis vulgaris) by using response surface methodology. Int. J. Agric. Crop Sci. 2013, 6, 89-96.

61. Gundogdu, M. Determination of antioxidant capacities and biochemical compounds of Berberis vulgaris L. fruits. Adv. Environ. Biol. 2013, 7, 344-348.

62. Hanachi, P.; Othman, F.; Motalleb, G. Effect of Berberis vulgaris aqueous extract on the apoptosis, sodium and potassium in hepatocarcinogenic rats. Iran. J. Basic Med. Sci. 2001, 11, 62-69.

63. Motalleb, G.; Hanachi, P.; Fauziah, O.; Asmah, R. Effect of Berberis vulgaris fruit extract on alpha-fetoprotein gene expression and chemical carcinogen metabolizing enzymes activities in hepatocarcinogenesis rats. Iran. J. Cancer Prev. 2008, 1, 33-44.

64. Kumar, S.; Narwal, S.; Kumar, V.; Prakash, O. $\alpha$-glucosidase inhibitors from plants: A natural approach to treat diabetes. Pharmacogn. Rev. 2011, 5, 19-29. [CrossRef]

65. Hajzadeh, M.A.R.; Rajaei, Z.; Shafiee, S.; Alavinejhad, A.; Samarghandian, S.; Ahmadi, M. Effect of barberry fruit (Berberis vulgaris) on serum glucose and lipids in streptozotocin-diabetic rats. Pharmacologyonline 2011, 817, 809-817.

66. Rahimi-Madiseh, M.; Karimian, P.; Kafeshani, M.; Rafieian-Kopaei, M. The effects of ethanol extract of Berberis vulgaris fruit on histopathological changes and biochemical markers of the liver damage in diabetic rats. Iran. J. Basic Med. Sci. 2017, 20, 552-556. [CrossRef] [PubMed]

67. Shidfar, F.; Ebrahimi, S.S.; Hosseini, S.; Heydari, I.; Shidfar, S.; Hajhassani, G. The effects of Berberis vulgaris fruit extract on serum lipoproteins, apoB, apoA-I, homocysteine, glycemic control and total antioxidant capacity in type 2 diabetic patients. Iran. J. Pharm. Res. 2012, 11, 643-652.

68. Moazezi, Z.; Qujeq, D. Berberis fruit extract and biochemical parameters in patients with type II diabetes. J. Nat. Pharm. Prod. 2014, 9, e13490. [CrossRef] [PubMed] 